IZA DP No. 6982

Security of Property as a Public Good: Institutions, Socio-Political Environment and Experimental Behavior in Five Countries

Francisco Campos-Ortiz

Louis Putterman

T.K. Ahn

November 2012
Loukas Balafoutas Mongoljin Batsaikhan

Matthias Sutter 


\title{
Security of Property as a Public Good: Institutions, Socio-Political Environment and Experimental Behavior in Five Countries
}

\author{
Francisco Campos-Ortiz \\ Bank of Mexico \\ Louis Putterman \\ Brown University \\ T.K. Ahn \\ Seoul National University
}

\author{
Loukas Balafoutas
}

University of Innsbruck

Mongoljin Batsaikhan
Georgetown University

\author{
Matthias Sutter \\ University of Innsbruck, University of \\ Gothenburg, IZA and CESifo
}

\section{Discussion Paper No. 6982 \\ November 2012}

\author{
IZA \\ P.O. Box 7240 \\ 53072 Bonn \\ Germany \\ Phone: $+49-228-3894-0$ \\ Fax: +49-228-3894-180 \\ E-mail: iza@iza.org
}

\begin{abstract}
Any opinions expressed here are those of the author(s) and not those of IZA. Research published in this series may include views on policy, but the institute itself takes no institutional policy positions. The IZA research network is committed to the IZA Guiding Principles of Research Integrity.

The Institute for the Study of Labor (IZA) in Bonn is a local and virtual international research center and a place of communication between science, politics and business. IZA is an independent nonprofit organization supported by Deutsche Post Foundation. The center is associated with the University of Bonn and offers a stimulating research environment through its international network, workshops and conferences, data service, project support, research visits and doctoral program. IZA engages in (i) original and internationally competitive research in all fields of labor economics, (ii) development of policy concepts, and (iii) dissemination of research results and concepts to the interested public.
\end{abstract}

IZA Discussion Papers often represent preliminary work and are circulated to encourage discussion. Citation of such a paper should account for its provisional character. A revised version may be available directly from the author. 
IZA Discussion Paper No. 6982

November 2012

\title{
ABSTRACT \\ Security of Property as a Public Good: Institutions, Socio-Political Environment and Experimental Behavior in Five Countries ${ }^{*}$
}

\begin{abstract}
We study experimentally the protection of property in five widely distinct countries - Austria, Mexico, Mongolia, South Korea and the United States. Our main results are that the security of property varies with experimental institutions, and that our subject pools exhibit significantly different behaviors that correlate with country-level property security, trust and quality of government. Subjects from countries with higher levels of trust or perceptions of safety are more prone to abstain initially from theft and devote more resources to production, and subjects from countries with higher quality political institutions are more supportive of protecting property through compulsory taxation. This highlights the relevance of sociopolitical factors in determining countries' success in addressing collective action problems including safeguarding property rights.
\end{abstract}

JEL Classification: $\quad$ C91, C92, D03, H41, P14

Keywords: property rights, theft, efficiency, experiment, socio-political factors

Corresponding author:

Matthias Sutter

University of Innsbruck

Department of Public Finance

Universitätsstrasse 15

6020 Innsbruck

Austria

E-mail: matthias.sutter@uibk.ac.at

\footnotetext{
* We thank Andrew Foster, Frans van Winden, and seminar participants at the Bank of Mexico, the University of Bonn, the Social Dilemmas Conference at Rice University, and the Thurgau Experimental Economics Meeting for helpful comments. We are grateful to Arjun Bansal for programming. Financial support through the Department of Economics at Brown University, the U.S. National Science Foundation grant SES-0921733, the Korea Research Foundation grant NRF-2010-330-B00077 and the University of Innsbruck is gratefully acknowledged. For their supporting roles on our research team, we thank Iñaki Arbeloa, Tom Chentong Xu, I Chen as well as Jorge Tarrasó in Mexico City, Benjamin Furlan in Innsbruck, Moon-Sun Kang, Sang-Hoon Ahn and Namun Cho in Seoul, and Amarsanaa Dashdavaa, Dulamzaya Batjargal, and Munkherdene Gochoo in Ulaanbaatar. This paper's findings, interpretations and conclusions are entirely those of the authors and do not necessarily reflect the views or policies of the Bank of Mexico.
} 


\section{Introduction}

Private property might strike us as the antithesis of a public good. Yet efficient protection of individuals' rights to property is to a large extent a problem of collective action. Where property rights are not protected by some combination of fear of penalties and voluntary norm compliance, individuals are forced to devote time and other resources to defending whatever wealth they are able to obtain, and their incentives to invest and to produce may be greatly attenuated. Societies that fail to achieve well-enforced property rights can therefore be expected to be poorer than those that do.

While social norms of desisting from theft contribute to a public good of secure property, private investment in defense of property (e.g., locks, alarm systems, barbed wire, and so forth) is also observed in every society. Well-functioning modern societies also assign much of the task of protection to collective institutions-police forces, courts, prison systems - capable of protecting the property of large numbers of individuals and thus achieving economies of scale. Of course, the mix of norm compliance, private protection, and collective protection of property varies across societies (Tabellini, 2008), making it an intriguing question how cultural traits interact with institutional constraints to shape the security of property.

Indeed, the correlation between cultural and institutional factors can be rather tight, as illustrated by Figure 1. It plots the level of property crimes in 56 countries on which data is available against the quality of government institutions (Panel A) and the level of trust (Panel B) in each country. ${ }^{1}$ As the two panels show, both effective national institutions and high trust among citizens exhibit inverse associations with the incidence of property crime in the full 56 country sample and in the five countries in which we conducted the experiments discussed below. At the same time, institutional and cultural variables are themselves highly correlated, as shown in Figure 2 by the correlation between the same governance and trust measures, again for both full sample and focal countries.

In this research, we present an experiment on property rights with three treatments that vary in terms of the level of institutional tools that subjects can utilize in solving the collective action problem of securing private property. We conduct the battery of

\footnotetext{
${ }^{1}$ We constructed measures of the incidence of property crimes, quality of political institutions and trust from the International Crime Victims Survey (United Nations), World Bank and World Values Survey data. See Appendix A for details.
} 
experiments in five economically, institutionally, and culturally distinct countries: Austria, Mexico, Mongolia, South Korea and the United States. These countries cover five out of eight regions in the World Values Survey cultural map (see Inglehart and Welzel, 2005, p. 63), allowing us to study how underlying socio-political differences intervene in the way institutions shape behavior. In total, we have 555 participants across the five countries. Within each country, we study experimentally a world in which individuals, organized in micro-societies of five subjects, can choose between productive, protective and appropriative activities and where material incentives make theft tempting.

Behaviors within each of our subject pools respond to treatment differences in qualitatively similar ways: without collective protection, the frequency of theft is above the social optimum, but less than half of what standard theory would predict. When the opportunity to engage in collective protection is made available but depends on strictly voluntary contributions, we observe statistically significant but economically modest improvement. Only when collective action is taken by a binding majority vote on a tax do we observe substantial efficiency gains through increased production.

Although reactions to the different institutional settings follow similar patterns, we find significant cross-country differences that are related to the socio-political environment within the countries of our experiment, which we proxy with measures of trust, perceptions of safety, and the quality of government. In particular, in countries with higher levels of trust or higher perceptions of safety, a higher fraction of subjects initially abstain from theft entirely, although an inability to sustain cooperation ultimately besets all subject pools. This initial difference suggests conditional willingness to adhere to an implicit non-theft norm, which generates different behaviors due to differing culturally-conditioned beliefs. Likewise, higher trust correlates with higher allocations of resources toward production, while stronger perceptions of lack of safety are associated with higher expenditures in protecting individuals' accumulations. Finally, in the treatment offering subjects the possibility to vote for mandatory funding of collective protection, subjects from countries with higher-quality political institutions are more prone to support that funding arrangement, making the protection of private property more cost-effective in their groups.

Together, these observations suggest an important role of socio-political factors in determining the success of institutions for addressing an important social dilemma, that of 
securing property rights and thus promoting productive activities. The varying success of the mandatory contributions mechanism, in particular, suggests that even incentivecompatible institutions may fail to produce theoretically efficient outcomes in the absence of a conducive socio-political atmosphere. Our results are also consistent with the hypothesis that differences in social capital help to explain differences in the quality of institutions and in economic performance (Knack and Keefer, 1997; Tabellini, 2008).

A number of economists, including Grossman (1991, 1994), Hirshleifer (1991, 1995), Skaperdas (1992), and Grossman and Kim (1995), have engaged in the theoretical study of the security of property by analyzing equilibrium allocations of resources between productive, protective, and appropriative activities in the absence of either external enforcement or norms. The basic general equilibrium framework of such papers has been extended to investigate the conditions under which the introduction of government favors the allocation of resources to production (Grossman, 2002). The seminal experimental paper is Durham, Hirshleifer and Smith (1998). They test, and largely confirm, the predictions of Hirshleifer's (1991) “Paradox of Power” hypothesis, according to which weaker or poorer parties may improve their position relative to stronger or richer opponents by engaging in conflict. Duffy and Kim (2005) assess the stability of an equilibrium in which agents devote resources to production, predation and defense against predation, as well as the effect of the introduction of a government. Powell and Wilson (2008) study experimentally the evolution of institutions in stateless societies by analyzing the level of efficiency in a Hobbesian state of nature, then offering subjects the opportunity to pledge support to a non-binding agreement not to engage in theft. ${ }^{2}$

Our experiment differs from those mentioned in several respects. Most importantly, ours is the first appropriation experiment to include subject pools in a diverse set of countries, which offers the possibility of assessing in a controlled way the operation of the same set of exogenously imposed institutions in different societies. In addition to this key difference, our subjects are neither assigned to nor required to choose between specialized producer or predator roles. Also, our focus on collective action and institutions leads us to introduce a novel collective protection technology with greater social but lower private

\footnotetext{
2 Additional experimental research on appropriative conflict include Carter and Anderton (2001), and Kimbrough, Smith and Wilson (2010).
} 
returns than private protection. And by running three different treatments, we can compare the effectiveness of collective protection technologies in both the absence and the presence of a state-like institutional structure (voting, taxation).

Our paper also adds to the literature examining how behaviors differ among countries or cultures through laboratory decision experiments, and to the still small strand of that literature combining experimental data with survey data drawn from representative national samples rather than from the experimental participants themselves (e.g., Herrmann et al., 2008; Thöni et al., 2012). We extend the approach to a specific problem of political economy not previously addressed by it, with an emphasis on the social dilemma feature of the property security issue that is often missing from its discussion.

The rest of the paper proceeds as follows. In Section 2, we spell out our experimental design and discuss the predictions of standard economic theory. Section 3 discusses our results. Section 4 concludes.

\section{Experimental design and predictions}

In each country, we study three treatments that share a common core structure. In each treatment, fixed-partner groups of five subjects each are formed. In each of 24 periods in total, each subject is endowed with ten "effort tokens" that he or she must allocate among three activities:

1. a productive activity that yields "wealth tokens" with diminishing returns. We denote the number of tokens for this activity by $m_{i}$ (for making wealth tokens);

2. theft directed at other group members' accumulation of wealth tokens, denoted by $T_{i}$ $=\Sigma_{\mathrm{j} \neq \mathrm{i}} t_{i j}$, where $t_{i j}$ indicates the theft tokens $i$ directs at a specific individual $\left.j\right)^{3}$; and

3. private protection $\left(p_{i}\right)$ of own accumulations from theft.

A fourth activity, collective protection, is available in two of the treatments and will be explained when these treatments are introduced.

\section{Table 1 about here}

\footnotetext{
${ }^{3}$ To make theft a live consideration from the outset, each subject is endowed with an initial accumulation of 100 wealth tokens at the beginning of the experiment.
} 
Table 1 shows the production function from effort to wealth tokens. Marginal returns decrease from 15 wealth tokens to one wealth token. In contrast to production, each effort token devoted to theft transfers a constant 10 wealth tokens from targeted individual $j$ 's accumulation to the targeting individual $i$ with probability of success $1-P_{j}$, where $0 \leq$ $P_{j} \leq 1$ is $j$ 's total level of protection stated as a probability that a given theft attempt against $j$ will be thwarted. Each of the $p_{j}$ effort tokens $j$ devotes to the private protection of her wealth accumulation raises $P_{j}$ by 0.1 . Each theft attempt by some individual $i$ against individual $j$ is governed by an independent random draw with the indicated probability. ${ }^{4}$

At the end of each period, subjects learn the number of wealth tokens they and each other group member accumulated by production and theft and the number lost by theft, and cumulative information on these categories is subsequently available in a "stats" screen that can be opened at any time. ${ }^{5}$ In the following sub-sections, we present the differences between treatments and discuss the subject pools and procedures.

\section{2.a NCP treatment - No Collective Protection}

In our first treatment, which we call No Collective Protection or NCP, subjects determined their allocations among production, theft and private protection simultaneously. We made collective protection unavailable to provide a benchmark against which to measure its effects when present. For subjects in this treatment, the experiment as a whole consisted of six four-period phases separated by one minute breaks, as shown by Panel A of Figure 3.a. The structure of the individual period is shown by Panel A of Figure 3.b.

Figure 3 about here

\footnotetext{
${ }^{4}$ The only exception to the rule regarding number of wealth tokens transferred occurs when a targeted subject's accumulation balance reaches zero. Because we prevent a subject's balance from becoming negative, those engaging in theft can split between them no more than the total accumulation a targeted subject has at the beginning of a period. We stipulate that this splitting is proportionate to the number of tokens each had allocated to theft from the targeted individual. Given that statistics on others' accumulations are always available and that those accumulations grow fairly large with time, the limitation was rarely binding. In more than 13,000 observations, the rule took effect only seventeen times.

${ }^{5}$ Group members have fixed letter identifiers throughout their sessions. Summary information on theft does not reveal who stole from whom, although that can be deduced if there is only one successful theft in a period.
} 
Considering the per-period constraint $m_{i}+T_{i}+p_{i}=10$, and assuming risk neutrality and self-interested payoff-maximization, the unique equilibrium of the stage game-and also the finitely repeated game-is the vector $\left(m_{i}, T_{i}, p_{i}\right)=(3,7,0)$. Three effort tokens are allocated to production because, provided there are no allocations to protection, each effort token devoted to theft would yield for i 10 wealth tokens, so only the first three tokens devoted to production could compete with theft in terms of expected marginal returns (see Table 1). There is no investment in private protection for the following reason. Assuming that others devote seven effort tokens to theft and that a subject herself is thus on average targeted by seven theft tokens, a subject expects to reduce her losses to theft by an average of $0.1 \times 70=7$ wealth tokens for each token devoted to protection, versus the ten she can gain from theft. So a risk-neutral agent would engage in no protective effort. Risk-aversion will not weigh in favor of private protection either, since allocating tokens to this activity introduces further variability to the expected returns.

It is clear that in the NCP treatment, our subjects face a social dilemma. If all refrain from engaging in theft and put ten tokens each period into production, each earns 70 tokens per period, versus the 39 tokens that are the equilibrium prediction for selfish, rational, nonrisk-loving agents. Abstinence from stealing can accordingly be thought of as a public good, and the $(3,7,0)$ equilibrium thus represents a failure of public goods provision. With this in mind we introduced, in the remaining two treatments, mechanisms of collective action which might help to establish better property protection.

\section{2.b VCP treatment - Voluntary Collective Protection}

In this treatment, each period has two stages. While the second stage is identical to the allocation stage of NCP, the first stage offers an opportunity for group members to voluntarily devote effort tokens to a collective protection fund-hence the treatment name Voluntary Collective Protection or VCP. Panel B of Figure 3.b shows the timing of the stage game. Each token assigned to this fund raises $P$ (the probability of protecting one's wealth against theft) of all members by 0.06 , up to a maximum of 12 tokens or $72 \%$ protection (a $28 \%$ probability of a theft succeeding). We impose a ceiling on the level of collective protection because we deem it realistic that property cannot be made $100 \%$ 
secure by public policing alone. ${ }^{6}$ Subjects are informed of the total level of collective protection before each makes her production, theft, and private protection decisions in the period's second stage.

Private and collective protection combine to determine $j$ 's total protection $P_{j}=$ $\min \left[0.1 p_{j}+\min \left(0.06 \Sigma c_{k}, 0.72\right), 1\right]$, where $c$ indicates contributions to collective protection and $k$ indexes any group member including $i$ and $j$. Notice that tokens allocated to private protection raise the protection level of only the allocator's accumulation by 10 percentage points, whereas tokens allocated to collective protection raise all group members' protection levels by 6 percentage points, making free-riding on collective protection a dominant strategy.

Denoting the number of tokens that individual $i$ allocates to collective protection by $c_{i}$, we can denote $i$ 's strategy by $\left(m_{i}, T_{i}, p_{i}, c_{i}\right)$, where $m_{i}+T_{i}+p_{i}+c_{i}=10$. Since we have already demonstrated that a risk-averse or risk-neutral subject wishing to maximize her earnings will allocate no tokens to private protection, it is clear from the above arguments that standard theory assuming self-interested agents also predicts that there will be no tokens allocated to collective protection, yielding as the unique equilibrium $(3,7,0,0)$.

Of course, this constitutes an inefficient social dilemma outcome. Assuming that the social optimum of $100 \%$ production and zero theft is out of reach, improving joint outcomes by provision of collective protection may yet be feasible for subjects with mild preferences for cooperation, because the amount assigned to the activity becomes public knowledge before the remainder of the period's allocation decisions are taken, allowing it to serve as a low cost cue of intent to cooperate. ${ }^{7}$ By putting only three tokens each into collective protection in the first stage, subjects can render it individually rational to assign the remaining seven tokens of each to production, leading to outputs of 64 wealth tokens per period instead of the 39 wealth token output that is otherwise predicted. ${ }^{8}$

\footnotetext{
${ }^{6}$ Note that since decisions are made simultaneously and without communication, over-allocation is possible. Group members learn the total contributions provided, but not the contribution of any individual member.

${ }^{7}$ By "preferences for cooperation," we refer to some kind of deviation from the standard economics assumption of exclusive concern for own money payoff. An example is conditional cooperation as discussed by Fischbacher and Gächter (2010).

${ }^{8}$ Clearly, it would be still more efficient were two subjects to allocate three tokens and three to allocate two tokens each to collective protection, leaving two more tokens for production. We discount this possibility as largely infeasible in the absence of a coordination device. Crawford, Gneezy and Rottenstreich (2008) show that coordination largely fails when subjects need to play asymmetric actions.
} 


\section{2.c VOTE treatment - Voting on collective protection}

Our third treatment, which we call VOTE, differs from VCP in that groups are given the opportunity to solve the free-riding problem surrounding collective protection by voting to make contributions mandatory - a scheme analogous to using taxes to fund a police force. Following a first phase of four periods in which no collective protection is available, as in NCP, group members vote before each of the remaining five phases (of four periods each) on whether to make contributions to collective protection mandatory or keep them voluntary. If a majority prefers mandatory contributions, then in the first stage of each of the following four periods, group members indicate their preferred level of contribution knowing that the median proposal will bind all; otherwise, periods take the same form as in VCP. Panel B of Figure 3.a shows the timeline of this treatment, while Panels B and C of Figure 3.b illustrate the timelines of the stage game for each of the two possible scenarios.

As Section 2.b showed, the equilibrium under the voluntary scheme is $(3,7,0,0)$, yielding average earnings of 39 wealth tokens per period. If the mandatory scheme is adopted, however, subjects can vote to mandate contributions of either two or three tokens to collective protection and thus make it individually rational to put the other tokens into production and have expected earnings of approximately 64 wealth tokens. ${ }^{9}$ A subject perceiving a positive probability of being pivotal should accordingly vote for the mandatory scheme, and without the means to coordinate voting, it is reasonable to expect all to vote this way. ${ }^{10}$ This yields 64 wealth tokens as expected earnings according to standard theory, or $91 \%$ of the potential earnings. This is much better than the expected 39 wealth tokens (or $56 \%$ of the maximum) in NCP.

While the VCP treatment also offers subjects a means of boosting efficiency through actions in stage 1 that raise incentives to engage in production in stage 2, it still entails a collective action dilemma unsolvable without voluntary cooperation. The VOTE treatment, in contrast, offers a way of mitigating the dilemma of property protection that

\footnotetext{
${ }^{9}$ Details regarding the indeterminacy of the optimal mandatory contribution (2 or 3 ) and the resulting indeterminacy of production are relegated to Appendix B; it suffices to note here that expected earnings of approximately 64 wealth tokens hold with either approach.

${ }^{10}$ Being unable to know for certain how others are voting, a subject cannot rule out that she will be pivotal, and this should eliminate her indifference. A trembling hand perfection argument can similarly be enlisted in favor of the prediction of uniform voting for the mandatory scheme.
} 
requires only self-interested rationality to operate. Standard economic theory thus predicts no greater efficiency in VCP than in NCP, but a large gain in efficiency in VOTE.

\section{2.d Subject pools}

Subjects' behavior toward the dilemma of property rights is likely to vary not only according to institutional contexts, which we control for with our treatments, but also with normative orientations and beliefs, which subjects bring with them into the lab. Hence, we conducted our experiment using subjects in a number of different countries having different historical and contemporary characteristics. ${ }^{11}$ The five countries in which the experiments were conducted-Austria, Mexico, Mongolia, South Korea and the United Statesrepresent a broad range of characteristics. Austria and the U.S. are economically developed, politically democratic societies, with Austria having considerably greater ethnic homogeneity and a long-standing social democratic institutional caste compared to the more individualistic free market qualities of the U.S. South Korea provides a more recently industrialized and democratized Asian setting with a less extensive welfare state, Confucian paternalistic traditions and a heavy dose of Western, Christian and modern technological influences. Mexico is an upper middle income developing country with a population of mixed Amerindian and Spanish origin which has experienced intermittent economic growth, partly facilitated by proximity to the United States, with a reputation for political instability, corruption, and, like South Korea, relatively recent effective democratization. Mongolia, which shares a high level of ethnic homogeneity with Austria and South Korea, is the least economically developed country in the sample. It is the only one to have gone through three generations under Communist rule before beginning a transition to free market capitalism in the 1990s, and is also the only one whose economy and society were based on semi-nomadic pastoralism rather than settled agriculture before modern times. Our sample accordingly represents three continents, five cultures (Inglehart and Welzel, 2005), a wide spectrum of economic development levels, a variety of levels of ethnic homogeneity, a range of experiences with democracy, and, as Appendix A illustrates,

\footnotetext{
${ }^{11}$ Noteworthy experiments suggesting cross-national differences between subject pools include Roth et al. (1992), Henrich et al. (2001), Herrmann, Thöni and Gächter (2008), Bohnet et al. (2008) and Bohnet, Herrmann and Zeckhauser (2010).
} 
additional differences with respect to quality of government, social trust, and perceived and experienced security of property.

\section{Table 2 about here}

At each site, sessions of all three treatments were conducted in a university computer lab using college-age students as subjects, each participating in no more than one session and thus only one treatment. In each country, six to eight groups of five members each participated in each treatment, with numbers varying due to variation in "show up" rates (see Table 2). All participants were similar in age, education and socio-economic position in their respective countries. Specific sites were the University of Innsbruck (Austria), the Instituto Tecnológico Autónomo de México or ITAM (Mexico City), the Mongolian University of Science and Technology or MUST (Ulaanbaatar), Korea University (Seoul) and Brown University (Providence, Rhode Island, U.S.) ${ }^{12}$

In Appendix C, we discuss the representativeness of our university student subject pools for their countrymen more generally by comparing their responses in our postexperiment survey to those in general surveys including the World Values Survey, and by briefly considering the results of two treatments using a non-student subject population in Mongolia.

\section{2.e Procedures}

Experiments were conducted between January and July of 2010 on computers programmed in Multistage (software initially developed at U.C.L.A. and Caltech). At the beginning of each session, instructions were read aloud in the relevant language while subjects read along on paper. ${ }^{13}$ In NCP and VCP, all instructions and practice took place before phase

\footnotetext{
${ }^{12}$ At four universities, subjects were drawn entirely from their own general undergraduate programs. The case of MUST is slightly different. This institution was selected as our site in Mongolia because it offered one of the few facilities in Ulaanbaatar with an adequate computer lab, but Mongolian student subjects were recruited from a total of nine institutions in the city, of which three, MUST, Mongolian National University, and Institute of Finance and Economics, account for the lion's share. We recruited from multiple universities because MUST lacks social science and humanities students, making its students less diverse than those in the other countries' subject pools.

${ }^{13}$ Instructions were translated from English to German, Korean, Mongolian and Spanish by native-speakers of each language belonging to our team and underwent "back-translation" to English by a different bilingual
} 
one. In VOTE, the initial instructions and practice before phase one, as well as phase one play, resembled those of NCP except that subjects were told that additional instructions would follow that phase. ${ }^{14}$ This was followed by further instructions describing collective protection and how to vote on it and determine its level. In all treatments, subjects were invited to ask questions of clarification before payoff-determining play commenced.

\section{Results}

\section{3.a Comparing play by treatment}

To simplify exposition, we first pool the data from our five sites and focus on differences among treatments, then turn to comparisons across sites in section 3.b. The four panels in Figure 4 display plots of average allocations to each of the four possible activitiesproduction, theft, private protection, and collective protection-while Figure 5 shows the resulting average earnings per subject and period. Table 3 compares our theoretical benchmarks to the actual average choices and outcomes by treatment.

Figures 4, 5 and Table 3 about here

Our first general observation is that in the NCP treatment, average token allocations to production (4.3) and theft (2.9) lie between the equilibrium prediction (3 to production and 7 to theft) and the social optimum (10 to production and 0 to theft). There are also substantial allocations to private protection-averaging 2.9 tokens-which are high enough to deter rational decision-makers from attempting further theft. Positive allocations to private protection are however at odds with the zero allocation predicted. In Appendix D we discuss three potential explanations to this conundrum: loss aversion, moral reservations against stealing, and asymmetric protective motives (i.e., following theft, a subject who anticipates retaliation may expect a higher return from protective investment). We

individual who had not read the English version to check for consistency. Instructions and practice scripts for all treatments in English are included in Appendix E.

${ }^{14}$ In the VOTE sessions, we had subjects play first under the NCP condition in order to reduce the amount of instructions to be absorbed at the outset and to lay the groundwork for subject appreciation of the potential uses of voted or voluntary collective protection arrangements. 
demonstrate the theoretical possibility of the first factor and find evidence for the last two factors.

As a result of the aforementioned choices in NCP, subjects earned an average of 46.6 tokens per period rather than the predicted 39, thus capturing about a quarter of the potential gain from cooperation but leaving the remaining three quarters "on the table.”15

In the VCP treatment, the average voluntary contribution to collective protection begins at 1.5 effort tokens per subject in period one, but declines rapidly, yielding an overall average of 0.4 tokens per period. Taking into account the average allocations of 2.7 tokens to private protection, the average subject's total protection level is about $40 \%$ in VCP (versus 29\% in NCP). This level renders the expected return to theft for a hypothetical subject with perfect foresight 6 wealth tokens, one less than the certain return on a $5^{\text {th }}$ token assigned to production. Presumably in part because of this higher protection, average allocations to production were 0.54 tokens higher than in NCP (4.83 vs. 4.29) and those to theft 0.84 tokens lower (2.01 vs. 2.85) — both differences being significant at the 1\% level according to a Mann-Whitney test using group averages as independent observations (see Table 4). Average earnings were thus 50.35 per period, 3.7 tokens higher than in the NCP treatment, a difference that is also significant at the $1 \%$ level. While modest, the introduction of a collective protection technology raises the percentage of potential cooperative surplus obtained by subjects by 12 percentage points, to $36.6 \%$ (cf. Table 3).

\section{Table 4 about here}

Recall that in theory, the VOTE treatment offers subjects their best opportunity to attain higher efficiency on the basis of individual rationality and self-interest. By voting to mandate the contribution of two or three tokens per subject to collective protection, sufficient protection can be assured so that allocating the remaining seven tokens to production becomes rational and thus about $80 \%$ of potential efficiency gains are attained. Figures 4 and 5 show that subjects did boost production and earnings in VOTE relative to

\footnotetext{
15 The potential gains from cooperation are 31, which is the difference between 70 (if all tokens are invested into production and no theft occurs) and 39 (the earnings in equilibrium).
} 
the first two treatments; collective protection also received a lift. Table 4 shows that these differences are statistically significant with $p<0.01$ according to Mann-Whitney tests. Hence, our VOTE treatment successfully illustrates the emergence of a tax-financed public policing institution. The impact is less than predicted, however, since the average efficiency gain in the five phases when the mandatory collective protection scheme was available is slightly under $50 \%$, rather than the predicted $80 \%$.

The failure to attain more of the potentially available gains in VOTE is largely explained by the facts that majorities voted to use the more efficient mandatory scheme in only $64 \%$ of the available opportunities and that the mandated collective protection level when the scheme was selected was not always ideal. Groups set contributions at three tokens in $10.3 \%$ of periods and at two tokens in 59.5\%, so an efficient scheme with mandatory contributions of either two or three tokens was in place in only about $45 \%(\approx$ $\left.(.103+.595)^{*} .64\right)$ of periods 5-24. Mandatory contributions of zero tokens, one token, and four tokens were chosen in 5\%, $25 \%$ and $0.2 \%$ of periods, respectively. Even in those periods in which groups selected the mandatory contributions of two or three tokens, allocations to production averaged only 6.05 rather than the privately optimal seven effort tokens, so earnings per period averaged 58.81 wealth tokens; this is significantly more than the 50.35 of the VCP treatment but still below the feasible 64 tokens. Also, we again see a surprising attraction to private protection. Subjects assigned an average of 1.13 (2.35) tokens to private protection when playing under the mandatory (voluntary) contribution scheme.

Summing up, the combined results across the five countries show that institutions matter. As in other social dilemma experiments, subjects achieve some level of cooperation under institutional settings of NCP and VCP in which they are not expected to do so based on standard economic theory, but cooperation wanes with time (see Figure 4). The opportunity for voluntary collective action in VCP allowed subjects to achieve higher levels of cooperation than they could in NCP, but the achievements were modest. Incentive-compatible institutional opportunity in VOTE further improved the outcome, as subjects utilized opportunities for making a binding contract to increase the level of production, but there was considerable variation in the degree to which different groups grasped the available benefits of this institution. 


\section{3.b Comparing play by country}

The pooled results reported in the previous subsection are representative of many aspects of the experimental outcome in each country, but hide differences across the five subject pools that we think give rise to the most interesting contribution of our study. In this and following subsection we focus on the differences across countries and check for the role of socio-political factors.

Figure 6 about here

Figure 6 shows average allocation to each of the four activities in the five countries separately. Before pointing out differences, it is useful to note the considerable number of qualitative similarities across countries. At all five sites, production is lowest in NCP, intermediate in VCP, and highest in VOTE, though the difference is negligible in two of the comparisons: between NCP (4.62) and VCP (4.63) in the U.S., and between VCP (4.57) and VOTE (4.62) in Mongolia. Allocations to theft are everywhere higher in NCP than in VCP or VOTE. ${ }^{16}$ In all countries, allocations to private protection are similar in NCP and VCP (only significantly different at the 10\% level in Mongolia), and lowest in VOTE. And collective protection is higher in VOTE than in VCP in every country, though again the difference is quite small in Mongolia.

\section{Table 5 about here}

Despite this considerable consistency, there are some important differences. Consider first the NCP and VCP treatments, in which voluntary cooperation offers the only possibility for increasing efficiency. Differences between the subject pools with regard to allocations to theft and protection (private in NCP, both private and collective in VCP) fail to attain statistical significance according to Kruskal-Wallis tests based on group averages as independent observations and country as the grouping variable (see Panels A and B of Table 5). However, Figure 6 shows suggestive differences in theft and protection

\footnotetext{
${ }^{16}$ In none of the countries is the difference between allocations to theft in VCP and VOTE statistically significant. As a corollary, theft choices are not statistically different between these treatments (see Table 4).
} 
allocations, and the corresponding differences in average allocations to production, are associated with statistically significant differences. This observation is confirmed by the results from Kruskal-Wallis tests shown in Table $5 .{ }^{17}$ In NCP, Austrian and U.S. subjects attain considerably higher production and hence efficiency than do Mongolians and Koreans, with Mexican subjects in between. The line-up in VCP is similar except that the U.S. subjects in this case join the Korean and Mongolian ones with lower efficiency. Adding to this the fact that highest efficiency is shown by the Austrians and lowest by the Mongolians also in VOTE treatment, there is a definite indication of between-country difference in proclivity/ability to cooperate.

More evidence of differences between subject pools in the pure social dilemma treatments can be found by focusing on behaviors in the first period. With forces common to all such settings tending to erode cooperation over time, the strongest evidence of differences in initial predispositions and beliefs may be displayed before subjects have received feedback of others' behaviors. Although Table 5 shows allocations to theft in NCP to be statistically indistinguishable when we consider the behaviors of all 24 periods, there are large and significant differences in period 1 choices. Average allocations to theft during the first period are statistically different with $p=0.07$ according to Kruskal-Wallis tests based on individual choices as independent observations and country as the grouping variable, with values going from 1.5 effort tokens in Austria to 2.6 tokens in Mongolia, and slightly above 2 tokens in the other countries. ${ }^{18}$ Decisions to engage in no theft at all may be especially revealing because, given the strong incentive to devote most of one's tokens to the activity, not stealing at all may represent an attempt to convey a desire to cooperate for mutual benefit, and choosing to do so may in turn reflect a belief that the likelihood that others are so disposed is not negligible. During the first period, the fraction of subjects who

\footnotetext{
${ }^{17}$ Mann-Whitney tests for every pair of countries reveal that the difference in allocations to production in NCP are statistically significant for Austria and South Korea $(p=0.018)$, Austria and Mongolia $(p=0.015)$, South Korea and Mexico $(p=0.082)$, South Korea and the U.S. $(p=0.036)$, Mexico and Mongolia $(p=$ 0.063, and Mongolia and the U.S. $(p=0.010)$. Parallel tests show the difference in allocations to production in VCP are significant between Austria and South Korea $(p=0.049)$, Austria and Mongolia $(p=0.007)$, and Austria and the U.S. $(p=0.021)$. Differences in average earnings parallel those in production.

${ }^{18}$ Kruskal-Wallis tests of allocation choices in period 1 in NCP need to be done at the individual level since subjects decide simultaneously in that period and have no previous interaction with other group members, so individual choices can be taken as independent observations. Because of the feedback subjects obtain regarding their fellow group members' performance starting at the end of period 1, group-level tests are required for allocations made after period 1 .
} 
decide to devote no resources to theft ranges from 38\% in the U.S. to 7\% in Mongolia, with Austria (29\%), Mexico (20\%) and South Korea (20\%) in between. A Kruskal-Wallis test indicates that these differences are statistically significant at the 5\% level. Further, "no theft” decisions in the first period are also statistically different according to Kruskal-Wallis tests both in VCP $(p=0.08)$ and VOTE $(p=0.012) .{ }^{19}$ These differences in initial decisions about theft show some alignment with differences in overall production and earnings outcomes, for instance with regard to Austria and Mongolia again being at or near the more and less cooperative ends of the spectrum, respectively.

A final notable difference is found in the VOTE treatment, where we observe considerable variation in institutional preferences among subject pools, with the proportion of individual votes in favor of the mandatory scheme ranging from $29.5 \%$ in Mongolia to 69.7\% in Austria, with the U.S. (58\%), Mexico (61.1\%) and South Korea (63\%) occupying the middle slots. The frequency of majority selection of the scheme follows a similar but not identical order, ranging from 22.5\% in Mongolia, to 62.5\% in the U.S., $75 \%$ in South Korea, 80\% in Austria and 82.9\% in Mexico. Panel C(i) in Table 5 shows that such differences in the preferences for and choice between the two schemes are statistically significant according to Kruskal-Wallis tests. ${ }^{20}$ Not surprisingly, these differences translate into significant differences in achieved production and earnings. Figure 6 shows a particularly wide gap between the Austrian and Mongolian subject pools, with the other three groups of subjects bunched together in between. ${ }^{21,22}$

\footnotetext{
19 Both Kruskal-Wallis and Mann-Whitney tests of "no theft" decisions in period 1 are performed at the individual level for the NCP and VOTE treatments as all decisions in that period are simultaneous so subjects have had no interaction with fellow group members. For the VCP treatment, in turn, group-level tests are more appropriate because theft choices are taken after group members learn about the level of collective protection, so individual choices are not fully independent. The tests find differences between subject pools that are statistically significant at the $10 \%$ level or better for Mongolian and Austrian, South Korean and U.S., Mexican and U.S. and Mongolian and U.S. subjects in NCP; for the Mongolian and Austrian, Mongolian and South Korean, Mongolian and U.S., Mexican and South Korean, and Mexican and U.S. subjects, in VOTE; and between Mongolian subjects and each other subject pool in VCP.

${ }^{20}$ In Mann-Whitney tests between subject pools using group-level observations, vote outcomes differ at the 5\% level in 2-tailed tests between Mongolia and Austria, South Korea and Mexico; and at the 10\% level in 1tailed tests between South Korea and Mexico, Mexico and the U.S., and Mongolia and the U.S.

${ }^{21}$ Mann-Whitney tests find that allocations to production differ overall (regardless of chosen institution) in phases 2-5 of VOTE between the Austrian and Mongolian and between the Mexican and Mongolian subject groups with $p<0.05$. The same pairs of countries show statistically significant differences in earnings, although the Austria-Mongolia difference is significant at the $10 \%$ level only. In the Kruskal-Wallis tests for differences by subject pool in phases $2-5$ regardless of chosen scheme, amount allocated to theft and amount allocated to collective protection both differ among countries with $p<0.10$.
} 


\section{3.c Socio-political environment and experimental choices}

Does the overall performance of each subject pool correspond in any way to economic outcomes of their respective countries? Figure 7 suggests this is the case by showing a positive relationship between countries' average GDP per capita (by purchasing power parity) over the last decade and the average earnings of wealth tokens per period that each subject pool attained across all treatments.

Figure 7 about here

What might account for the correlation between country incomes and success in providing the public good of secure property in our experiment? Identifying a single definitive factor is impossible, since so many institutional, cultural, and socioeconomic factors are so highly correlated in the relevant international data and since we have experimental observations from five countries only. Nonetheless, we think it plausible to suggest that the main mechanism at work is social capital or trust which is closely associated with the level of security of property and of persons in the societies in question (Figure 1, Panel B) and with the quality of their governmental institutions (Figure 2). In a society in which theft and violence are experienced relatively rarely by most individuals, people are likely to have a higher level of trust in others. As experimental subjects, they are also likely to assign a higher probability to others upholding during the experiment the prohibition on theft that is the law outside the lab. Furthermore, in a society in which people feel they can trust the public authorities to implement laws fairly and trust their fellow citizens to make sensible use of their democratic rights, subjects are likely to have less hesitation about addressing the property protection issue through binding, democratically set taxes.

While formal statistical proof of the factors underpinning the cross-country differences in our results is ruled out by our small number of country observations, we illustrate the correlations that support our intuitions with a series of cross-country plots. The premise of these exercises is that subjects' behaviors in the lab are (partly) shaped by the same intricate social, cultural and political forces that determine their behavior in naturally

\footnotetext{
${ }^{22}$ Conditional on the choice of the mandatory scheme, however, Panel C(ii) of Table 5 shows that behaviors are statistically indistinguishable across countries. There are some differences in behavior among groups operating under the independent contributions scheme (see Panel C(iii)), but we do not focus on them because in most subject pools, groups operating under it are few and likely to be unrepresentative (see Table 6).
} 
occurring settings. We stress that the measures we utilize as proxies of each country's socio-political environment are themselves highly correlated, so replacing one gauge with another generates similar visual impressions. For this reason, we make no claims of causality and we view our exercises more in the spirit of illustration. For the sake of parsimony, we will with one exception focus on mean experimental outcomes across all three treatments.

In a first exercise, we provide evidence that subjects from countries with better perceptions that property is secure and higher levels of trust among people are more prone to abstain from theft entirely at the start of the experiment. To measure perceptions of safety, we exploit data from the United Nations' International Crime Victims Survey $(\mathrm{ICVS})^{23}$ to construct a composite index aimed at capturing how safe people feel in each country. We built this index via factor analysis ${ }^{24}$ of the responses to the survey questions (i) "How safe do you feel walking alone in your area after dark? (1=very safe, 2=fairly safe, 3=a bit unsafe, 4=very unsafe)," and (ii) "What would you say are the chances that over the next twelve months someone will try to break into your home? (1=very likely, 2=likely; 3=not very likely)”. A higher value of the index reflects a perception that people and their possessions are at higher risk. Our results indicate that, among our sites, Mongolians feel the least safe, followed by Mexicans and South Koreans, with Austrians and Americans exhibiting the highest perceptions of safety. As a measure of trust, we employ a "Trust Index" that captures the difference between the share of national respondents to the most recent World Values Survey or similar regional survey who chose "Most people can be trusted" and the share of respondents who chose "You can’t be too careful” in response to the question "Generally speaking, would you say that most people can be trusted, or that you can't be too careful in dealing with people?”25 Thus, a higher score of the trust index entails more trust among people. According to this measure, people from the U.S. and Austria trust others the most, followed by South Koreans and Mexicans, while Mongolians

\footnotetext{
${ }^{23} \mathrm{http} / / /$ www.unodc.org/unodc/en/data-and-analysis/Crime-Victims-Survey.html

${ }^{24}$ See Johnson and Wichern (2002) for a detailed description of factor analysis methods. We implemented this technique using the factor/predict commands in Stata.

${ }^{25}$ The Trust Index captures the difference between the shares of responses rather than just the fraction of respondents who chose "Most people can be trusted" in order to adjust for the "No Answer" option that is offered in some of the regional surveys, or for slight differences in wording (e.g., by framing the question as a statement with which respondents would agree or not).
} 
are the most careful in their interaction with others. Appendix A provides further details on these measures.

\section{Figure 8 about here}

Panel A of Figure 8 displays the inverse relationship between our measure of perceived lack of safety index and the fraction of subjects who do not allocate any resources toward stealing from their fellow group members in period one. Panel B exhibits the positive association between the trust index and the same experimental outcome. These results provide support to the idea that subjects condition their initial adherence to an implicit non-theft norm on the belief that others will do the same. Although the number of subjects completely abstaining from theft declined rapidly after the first period as subjects learned that not all in their group were so norm-following, subject pools in which more individuals initially abstained from theft still tended to produce more, on average, over the course of their sessions.

\section{Figure 9 about here}

Our conjecture that trust lies at the root of cooperation and hence production choices in our experiment finds illustrative support when we graph the country-level trust measure against average allocations to production over all periods and treatments, as shown in the left panel of Figure 9. Arguably, moreover, subjects' socio-political environment plays a more prominent role in shaping choices at the outset of the experiment, before the natural unfolding of the game introduces additional incentives that sway behaviors in different directions. Hence, period one choices offer more pristine evidence of the influence that socio-political conditions exert on individuals' behaviors. When we focus on period 1 production allocations, we find a stronger correlation between trust and production, as the right panel of Figure 9 shows.

Next, we check for the correlations between perceptions of safety and allocations to protective activities. The motivation of this exercise stems from the notion that if individuals face conditions of poor security of their property, they would dedicate a higher share of resources to defend their wealth at the expense of productive activities. 
Figure 10 about here

The left panel of Figure 10 shows that subjects from countries where people feel less safe tend, on average across all periods and treatments, to allocate more resources to private protection. The right panel exhibits a stronger positive correlation between the perceived lack of safety and initial allocations to private protection.

\section{Figure 11 about here}

Similar patterns are observed regarding allocations to collective protection. The left panel of Figure 11 displays a positive relationship between the extent to which people feel unsafe and average amount of tokens utilized for collective protection across all periods. The fit becomes considerably stronger when we focus on period one, as shown by the right panel. Checking for initial allocations to collective protection is particularly relevant in this case because there is one clear force (free riding) determining contributions in VCP that becomes a more dominant driver of contribution choices as the experiment progresses.

\section{Figure 12 about here}

The VOTE treatment invites cross-country comparison because it is the only one in which our subjects decide on the use of an institution and the level of a tax by voting. We wondered whether differences in the quality of the political institutions among the countries represented could help to explain some of the cross-country variation in the support for

provision of collective protection by mandating tax-like contributions. To explore this issue, we constructed a composite "Governance Index” applying factor analysis methods to three variables included in the World Bank’s Worldwide Governance Indicators (WGI) dataset: government effectiveness, rule of law and control of corruption. A higher value of our Governance Index reflects political institutions of higher quality. Of the countries included in this study, Austria exhibits the highest Governance Index, followed by the U.S., South Korea and Mexico, with Mongolia having the lowest score (see Table A4 in Appendix A, where we also provide definitions for the components of the index). 
Figure 12 shows a positive association between our Governance Index and the share of individual votes for the mandatory scheme. Although the positive correlation is mainly driven by the two countries on the extremes of the governance spectrum, Mongolia and Austria, the overall pattern suggests that subjects from countries with political institutions of higher quality are more prone to support the government-like institution meant to foster efficiency.

\section{Conclusion}

We used laboratory decision-making experiments to study how groups of individuals may attempt to establish secure rights to property that permit a socially efficient allocation of resources to production. In addition to a purely anarchic setting (NCP) in which voluntary abstinence from theft and a private protection technology are the only ways to make property secure, we studied two treatments that incorporate a technology of collective property protection simulating real world counterparts (e.g., police). This collective protection technology adds a second social dilemma element, reinforcing the idea that property rights are a public good. We conducted all treatments with undergraduate subjects in five economically, institutionally, and culturally distinct countries: Austria, Mexico, Mongolia, South Korea and the U.S.

Our results in the treatments without voting, i.e., in NCP and VCP, echo those of more standard voluntary cooperation experiments. Attempts to cooperate are rarely entirely absent, especially in the initial periods of play, as indicated in our data by the fact that 30 $40 \%$ of subjects completely refrained from theft in first period play in the NCP treatment in the Austrian and U.S. subject pools. But cooperation tended to unravel with repetition much as in the canonical voluntary contribution mechanism (Ledyard, 1995), so overall efficiency was closer to the non-cooperative equilibrium prediction than to the social optimum. About a quarter of potential gains from cooperation were achieved in NCP, and slightly over a third in VCP.

In our VOTE treatment, a majority of subjects voted rationally to fund collective protection by a mandatory levy, illustrating how governments help to address the dilemma of property in modern societies. With a substantial minority of votes favoring the non- 
mandatory institution and with frequent choice of lower-than-efficient tax levels, however, the institutional solution fell short of its theoretical potential. Nevertheless, introducing mandatory collective protection in VOTE led to the highest levels of efficiency gains in all countries, reaping almost 59\% of potential efficiency gains, which is significantly better than in VCP (37\%) and NCP (25\%).

Perhaps most interesting is our finding of considerable variation across countries, correlating with differences in country characteristics that are suggested by large-scale surveys. Our findings support the view that underlying socio-political conditions are important to the security of property rights and that these conditions vary in a manner which also affects whether effective institutions will be built in a society, as evidenced by the failure of the majority of Mongolian groups to adopt the tax-like scheme. Also, we find that many individuals seem willing to refrain from theft conditional on others not stealing, which makes expectations of the proportion of others who would steal an important determinant of initial cooperation (e.g., only 10\% of Mongolian subjects refrained from first period theft in the same treatment that saw three to four times more Austrian and U.S. subjects do so). Assuming that expectations of the frequency of theft within subject pools are correlated with people's perceptions of how secure their property is, or the trust they have in others, helps to explain observed cross-country variation in allocations to protection. Our findings also provide support to the view that social capital facilitates cooperation, thereby promoting economic efficiency. And differences in the quality of political institutions help to understand the variation in subjects' inclination to employ a mechanism akin to a government to fund collective protection from theft: almost $70 \%$ of Austrian subjects but less than $30 \%$ of Mongolian ones voted to make contributions to collective protection mandatory in the VOTE treatment.

Many of our results invite interpretations applicable to a broad class of collective action dilemmas. Nevertheless, we would like to conclude by noting that our experiment delivers several findings particularly relevant to the problem of property rights. The choices of our experimental subjects support the argument that normative constraints may play a part in making property secure, but that they require supportive initial beliefs and channels of reinforcement. The operation of institutions to support collective action is likewise shown to be possible, but not automatic. The underpinnings of effective norms and good 
institutional choices are to a significant degree historically and culturally contingent. Crosscountry evidence from outside of the lab may also be called on in support of the idea that secure property rights are requirements of more productive economies. The fact that the per capita incomes of the five countries from which our subjects were drawn are positively associated with perceptions of safety, social trust, quality of government institutions, and ultimately with the efficiencies achieved in the lab by our subjects, suggests interconnections that are worthy of further study. 


\section{References}

Bohnet, Iris, Fiona Greig, Benedikt Herrmann and Richard Zeckhauser, 2008, "Betrayal Aversion: Evidence from Brazil, China, Oman, Switzerland, Turkey, and the United States,” American Economic Review, 98: 294-310.

Bohnet, Iris, Benedikt Herrmann and Richard Zeckhauser, 2010, “Trust and the Reference Points for Trustworthiness in Gulf and Western Countries,” Quarterly Journal of Economics, 125: 811-28.

Carter, John R. and Charles H. Anderton, 2001, “An Experimental Test of a Predator-Prey Model of Appropriation,” Journal of Economic Behavior and Organization, 45: 83-97.

Crawford, Vincent P., Uri Gneezy, and Yuval Rottenstreich, 2008. "The Power of Focal Points is Limited: Even Minute Payoff Asymmetry May Yield Large Coordination Failures.” American Economic Review, 98(4): 1443-1458.

Duffy, John and Minseong Kim, 2005, “Anarchy in the Laboratory (and the Role of the State),” Journal of Economic Behavior and Organization, 56: 297-329.

Durham, Yvonne, Jack Hirshleifer and Vernon L. Smith, 1998, "Do the Rich Get Richer and the Poor Poorer? Experimental Tests of a Model of Power,” American Economic Review, 88: 970-83.

Fischbacher, Urs and Simon Gächter, 2010, “Social Preferences, Beliefs, and the Dynamics of Free Riding in Public Good Experiments,” American Economic Review, 100: 54156.

Grossman, Herschel, 1991, “A General Equilibrium Model of Insurrections,” American Economic Review, 81: 912-21.

Grossman, Herschel, 1994, "Production, Appropriation, and Land Reform,” American Economic Review, 84: 705-12.

Grossman, Herschel, 2002, “Make Us a King: Anarchy, Predation, and the State,” European Journal of Political Economy, 18: 31-46.

Grossman, Herschel and Minseong Kim 1995, "Swords of Plowshares? A Theory of the Security of Claims to Property,” Journal of Political Economy, 103: 1275-88.

Henrich, Joseph, Robert Boyd, Samuel Bowles, Colin Camerer, Herbert Gintis, Richard McElreath and Ernst Fehr, 2001, "In Search of Homo Economicus: Experiments in 15 Small-Scale Societies,” American Economic Review, 91: 73-79. 
Herrmann, Benedikt, Christian Thöni and Simon Gächter, 2008, “Antisocial punishment across societies,” Science, 319: 1362-7.

Hirshleifer, Jack, 1991, “The Paradox of Power,” Economics and Politics, 3: 177-200.

Hirshleifer, Jack, 1995, “Anarchy and its Breakdown,” Journal of Political Economy, 103: 26-52.

Inglehart, Ronald and Christian Welzel, 2005, Modernization, Cultural Change and Democracy, New York, NY: Cambridge University Press.

Johnson, Richard and Dean Wichern, 2002, Applied Multivariate Statistical Analysis, $5^{\text {th }}$ Edition, Upper Saddle River, NJ: Prentice Hall.

Kimbrough, Erik, Vernon Smith and Bart Wilson, 2010, "Exchange, Theft, and the Social Formation of Property,” Journal of Economic Behavior and Organization, 74: 206-29.

Knack, Stephen and P. Keefer, 1997, "Does Social Capital Have an Economic Payoff? A Cross-Country Investigation,” Quarterly Journal of Economics, 112:1251-88.

Ledyard, John O. (1995), “Public Goods: A Survey of Experimental Research,” in John Kagel and Alvin Roth, eds., The Handbook of Experimental Economics, Princeton, NJ: Princeton University Press.

Powell, Benjamin and Bart Wilson, 2008, “An Experimental Investigation of the Hobessian Jungles,” Journal of Economic Behavior and Organization, 66: 669-86.

Roth, Al, Vesna Prasnikar, Masahiro Okuno-Fujiwara and Shmuel Zamir, 1992, "Bargaining and Market Behavior in Jerusalem, Ljubljana, Pittsburgh, and Tokyo: An Experimental Study,” American Economic Review, 81: 1068-95.

Skaperdas, Stergios, 1992, “Cooperation, Conflict, and the Power in the Absence of Property Rights,” American Economic Review, 82: 720-39.

Tabellini, Guido, 2008, “Institutions and Culture,” Journal of the European Economic Association, 6: 255-94.

Thöni, Christian, Jean-Robert Tyran and Erik Wengström, 2012, “Microfoundations of Social Capital,” Journal of Public Economics, 96: 635-43. 
Figures and Tables

Figure 1: Governance, Trust and Incidence of Property Crimes

Panel A

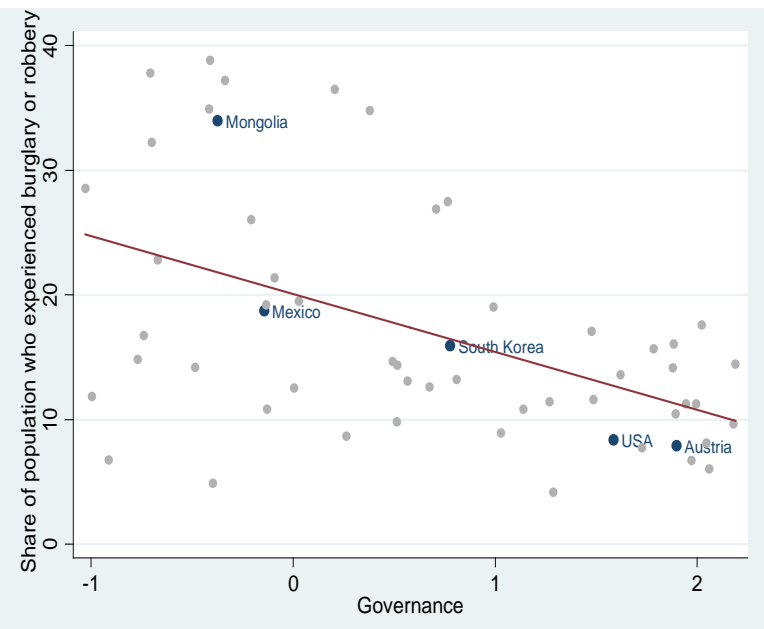

Panel B

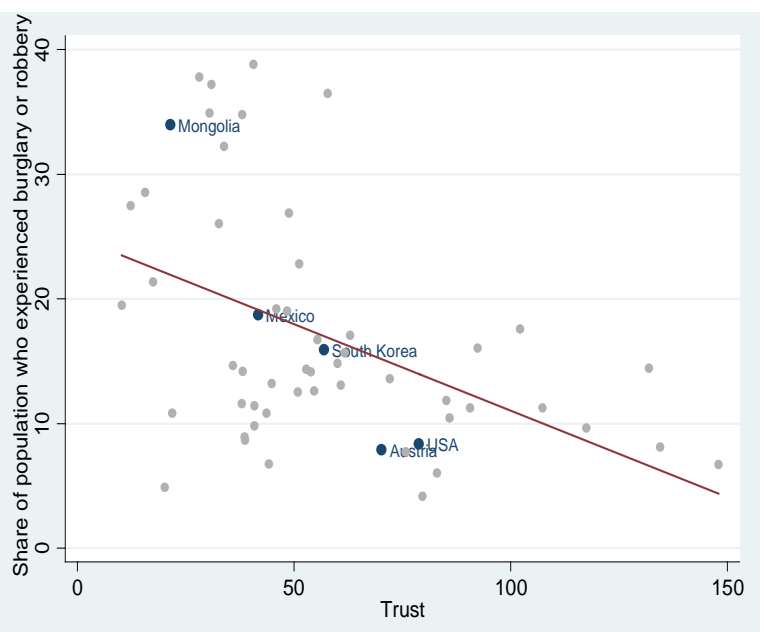

Figure 2: Governance and Trust

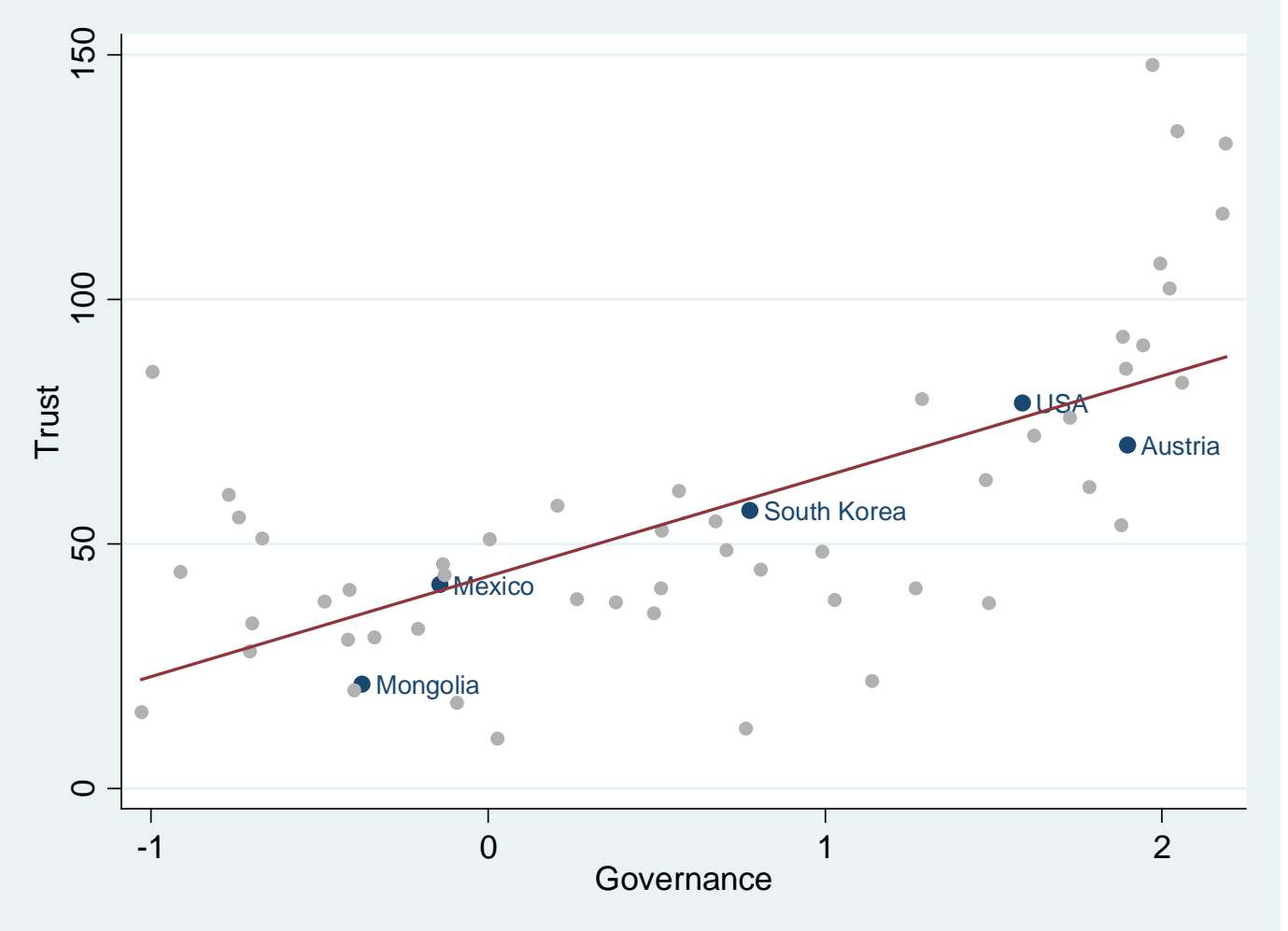




\section{Figure 3.a: Session timelines for each treatment}

Panel A: NCP and VCP

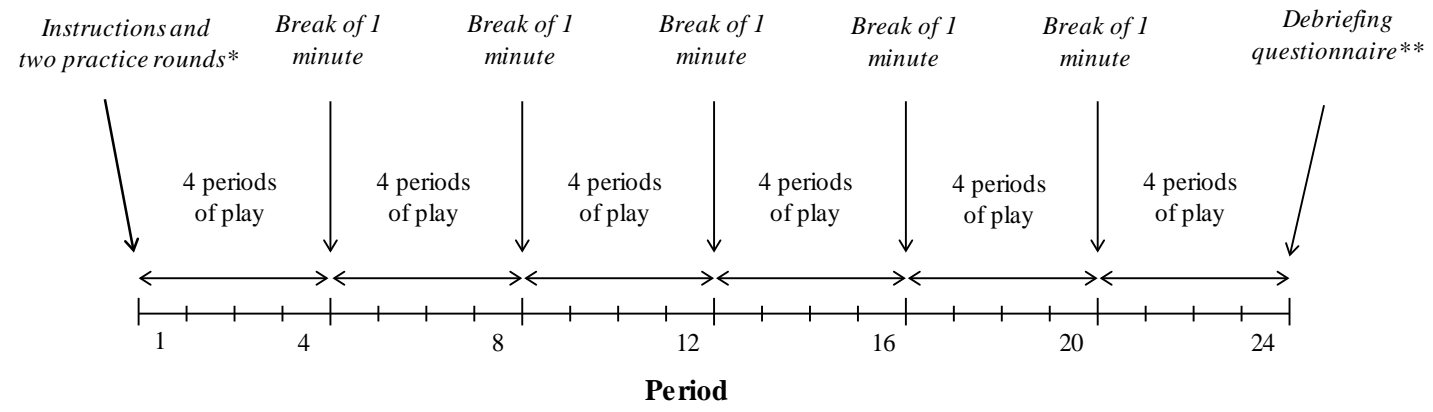

Panel B: VOTE

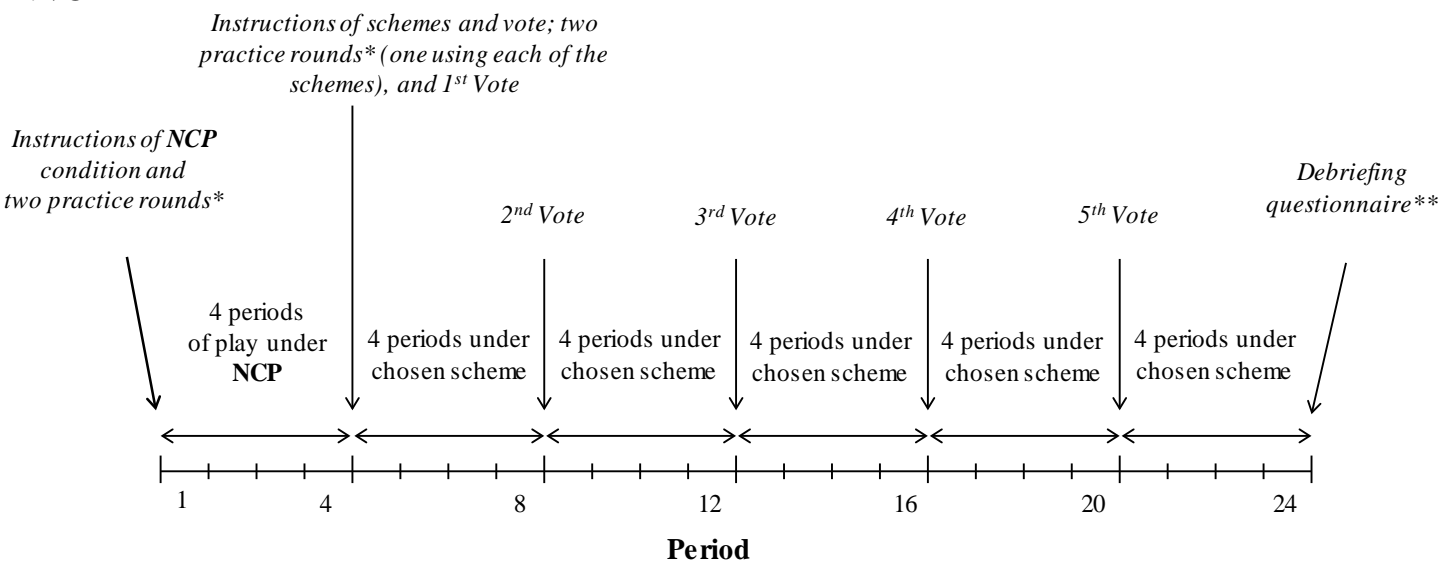

* Practice rounds were guided by experimenter directions for familiarization with the software interface and without indications of others' likely choices.

** In Austria, Korea, Mongolia and the U.S., sessions ended with a debriefing questionnaire. In Mexico, subjects completed the questionnaire several days before their participation in the lab; sessions ended with subjects writing down their comments about the experiment. 


\section{Figure 3.b: Timelines of stage games for each treatment}

Panel A: NCP

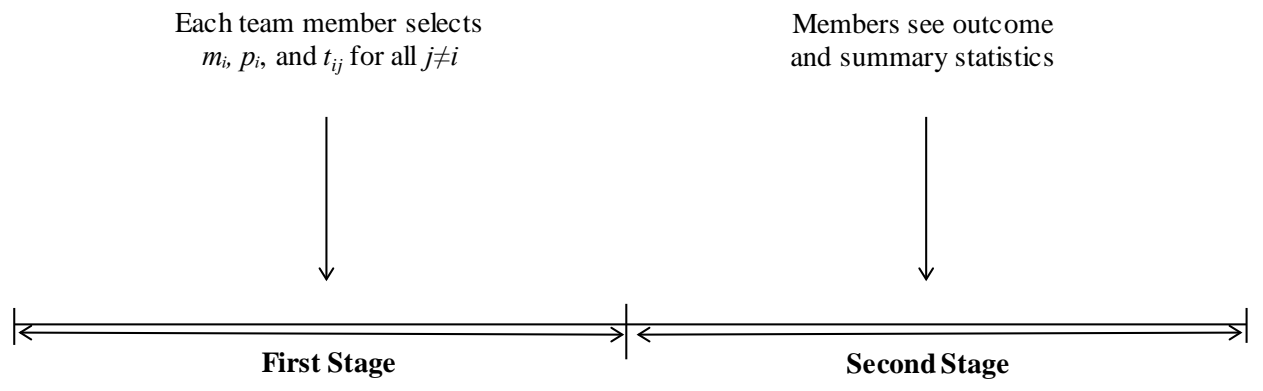

Panel B: VCP and VOTE if the independent contributions scheme is chosen

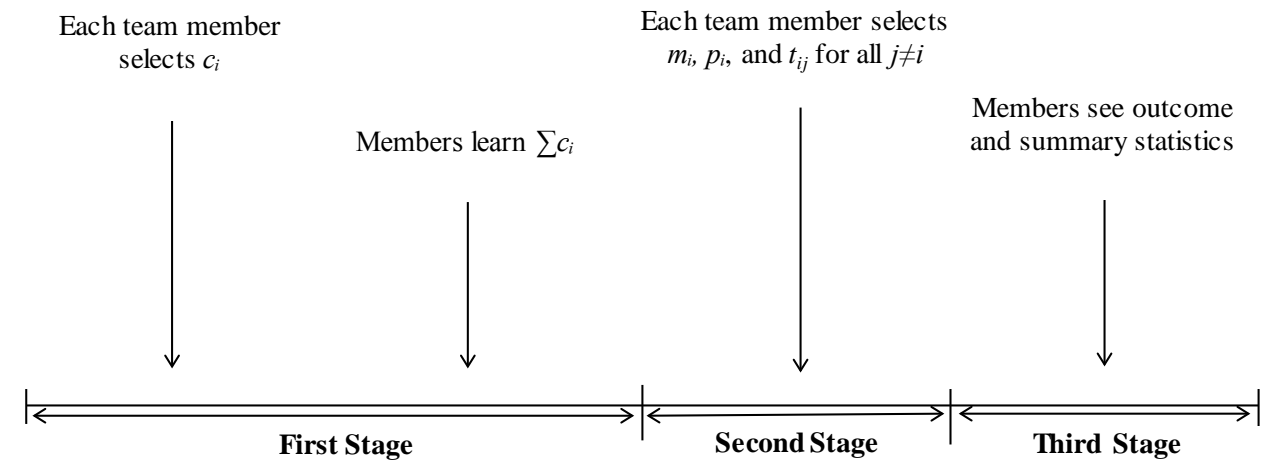

Panel C: VOTE if the mandatory contributions scheme is chosen

Each team member proposes $c_{i}$
Each team member selects $m_{i}, p_{i}$, and $t_{i j}$ for all $j \neq i$

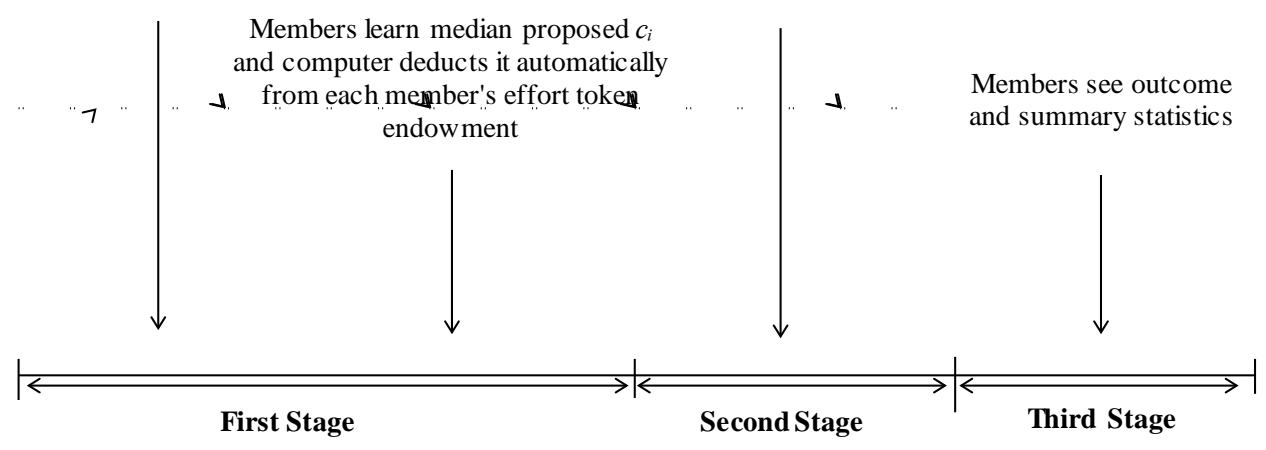


Figure 4: Average allocations by period and treatment

Production

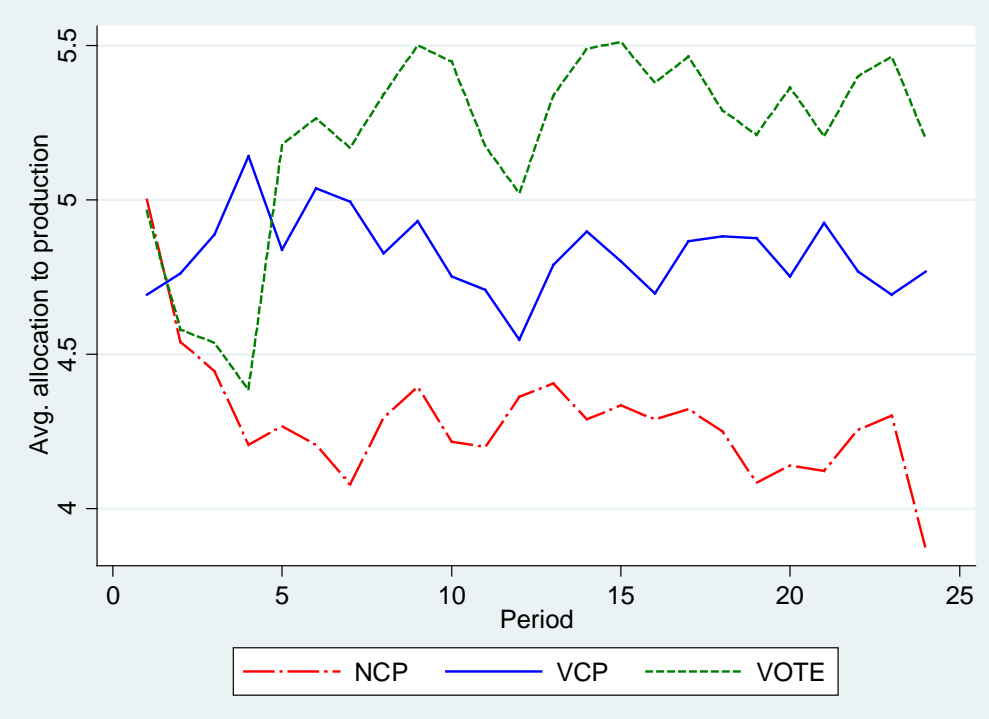

Private protection

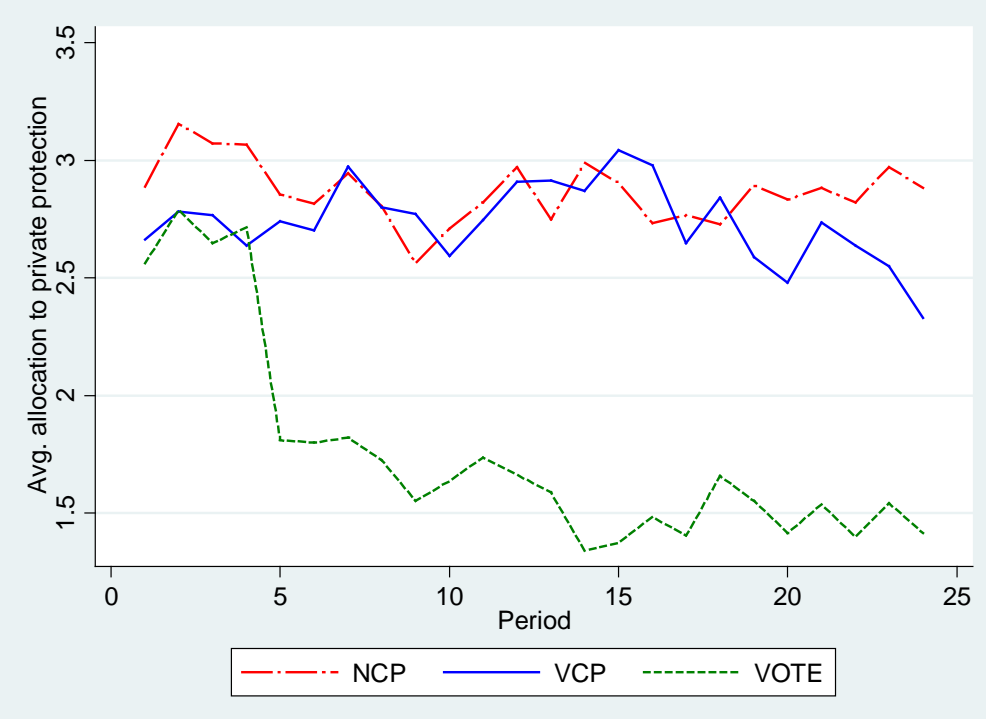

Theft

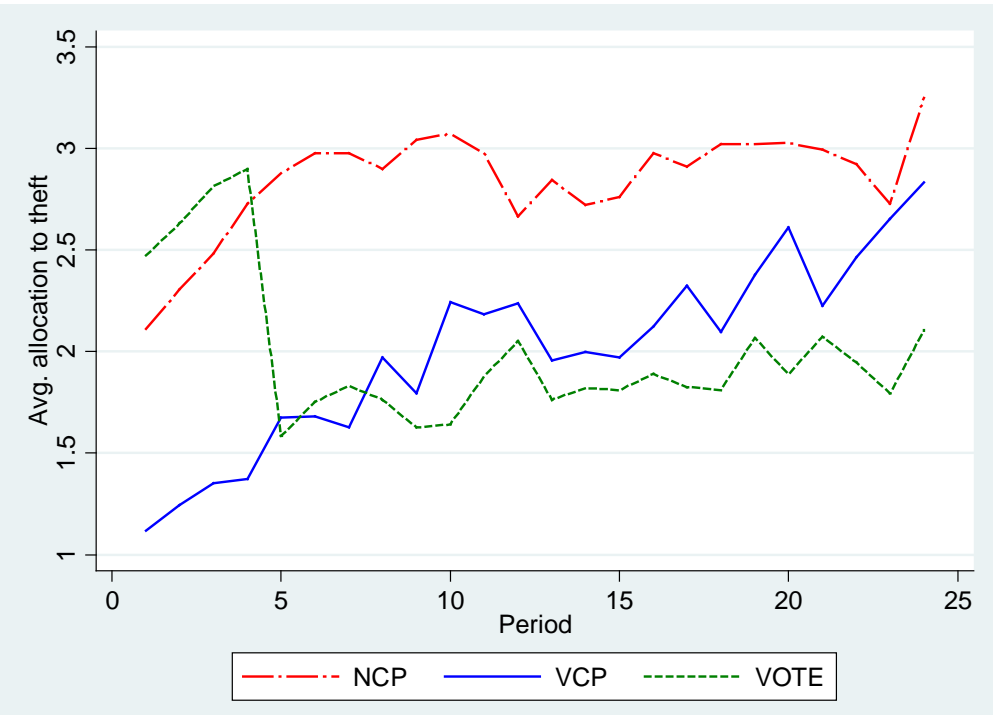

\section{Collective protection}

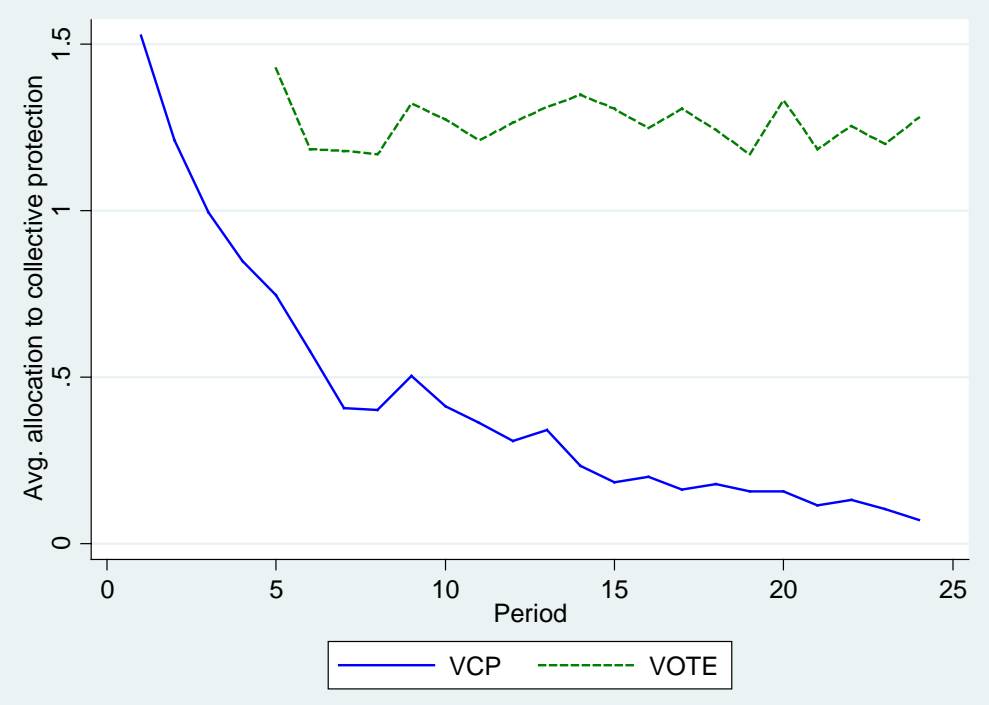


Figure 5: Average earnings by period and treatment

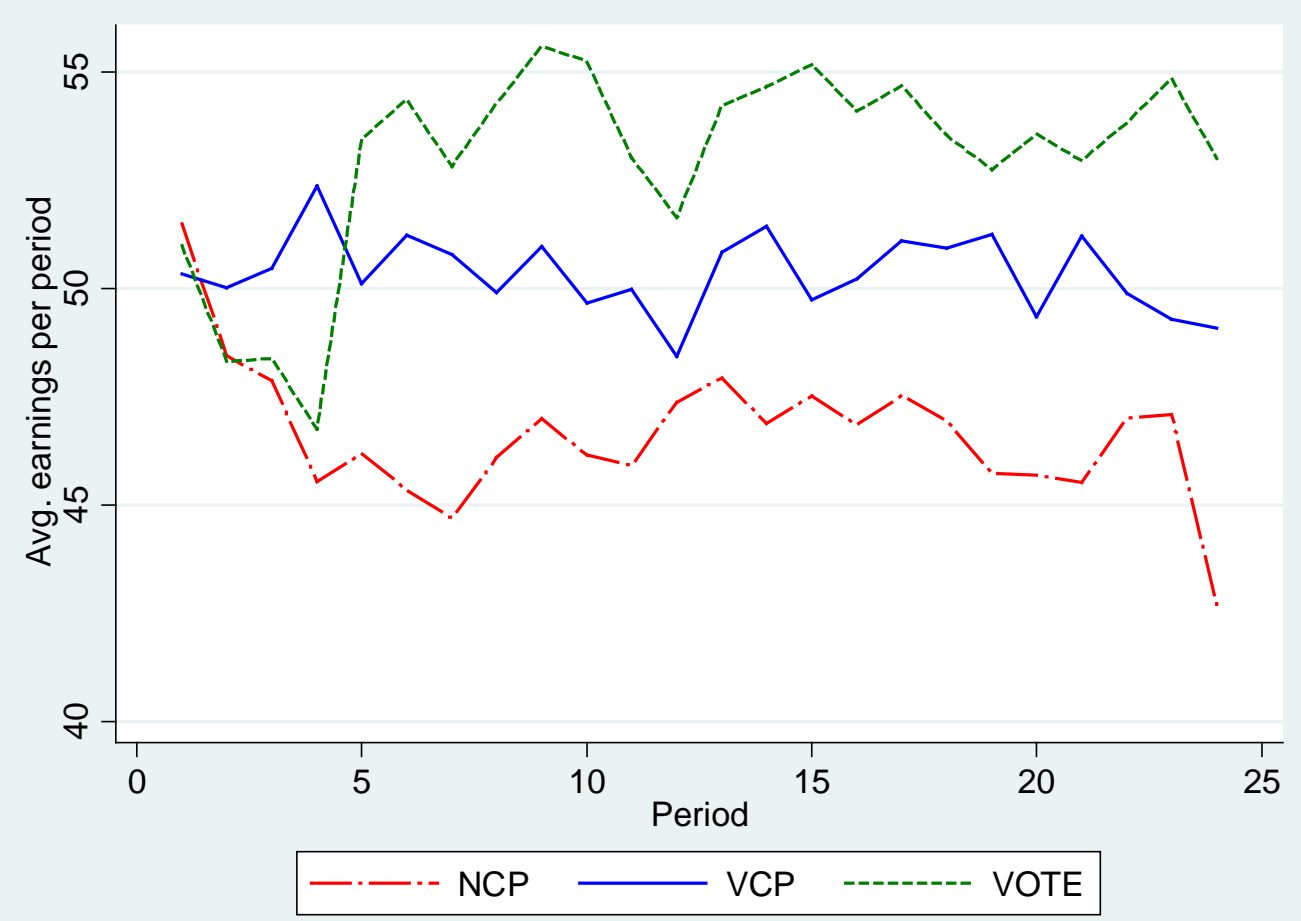


Figure 6: Average allocations by country and treatment

Production

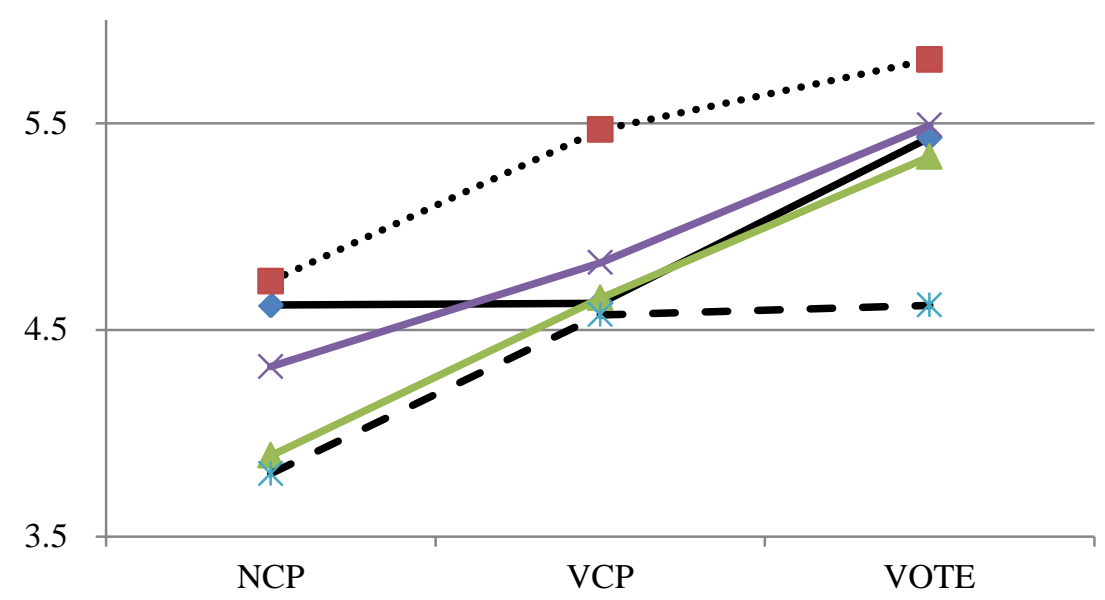

Private protection

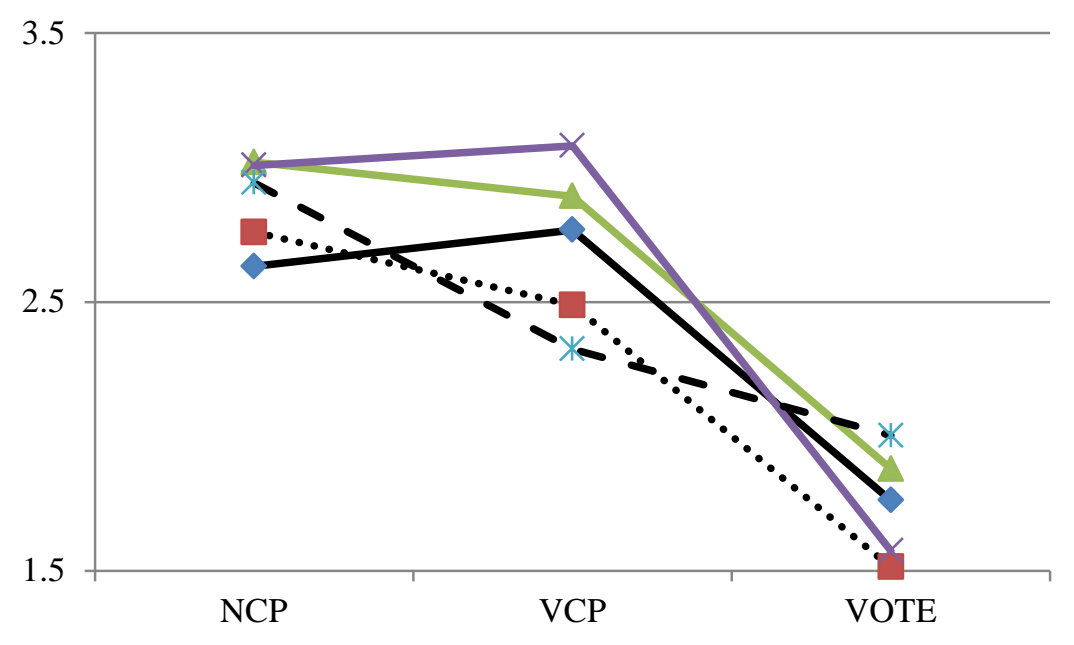

Theft

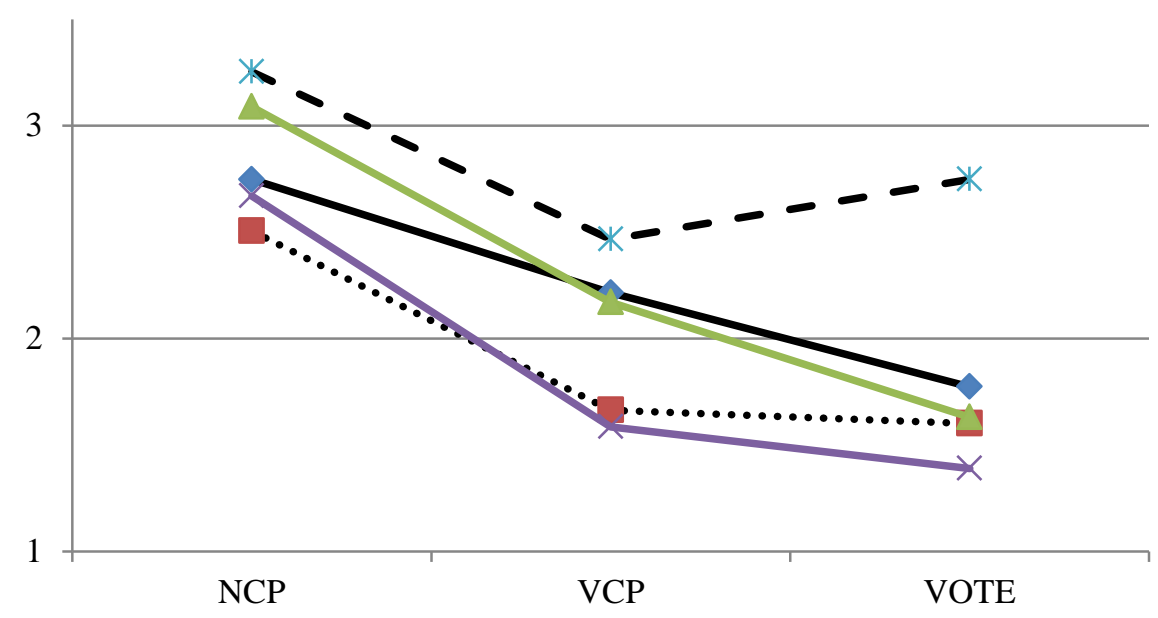

Collective protection

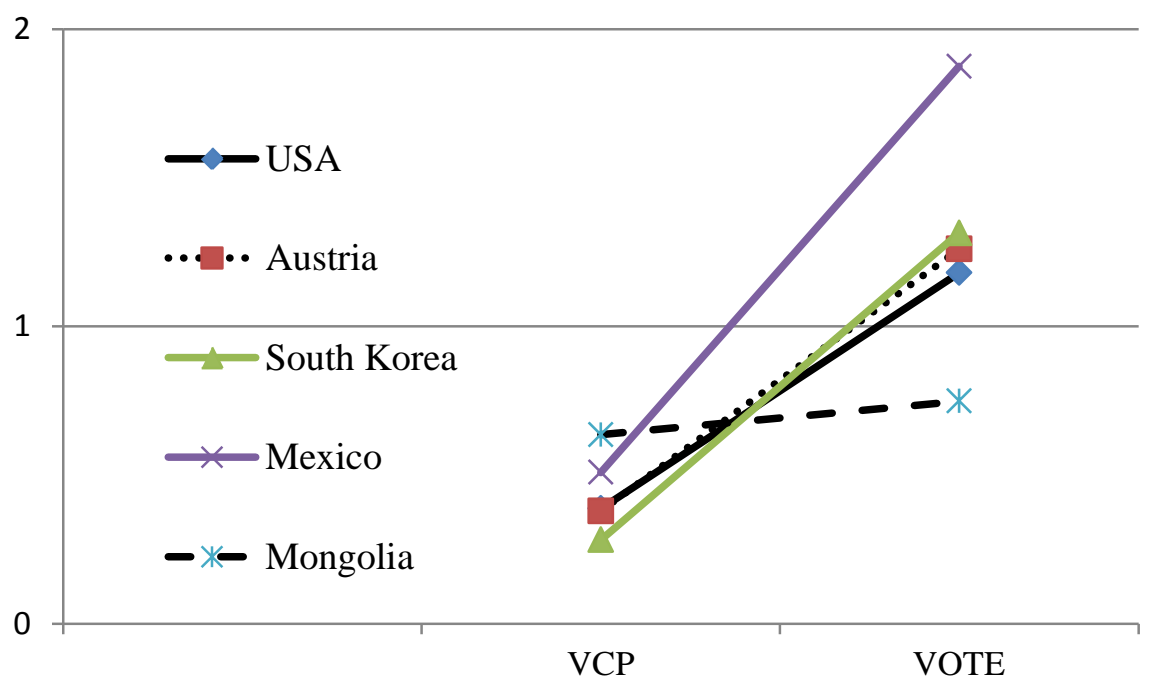


Figure 7: GDP per capita and earnings of wealth tokens per period

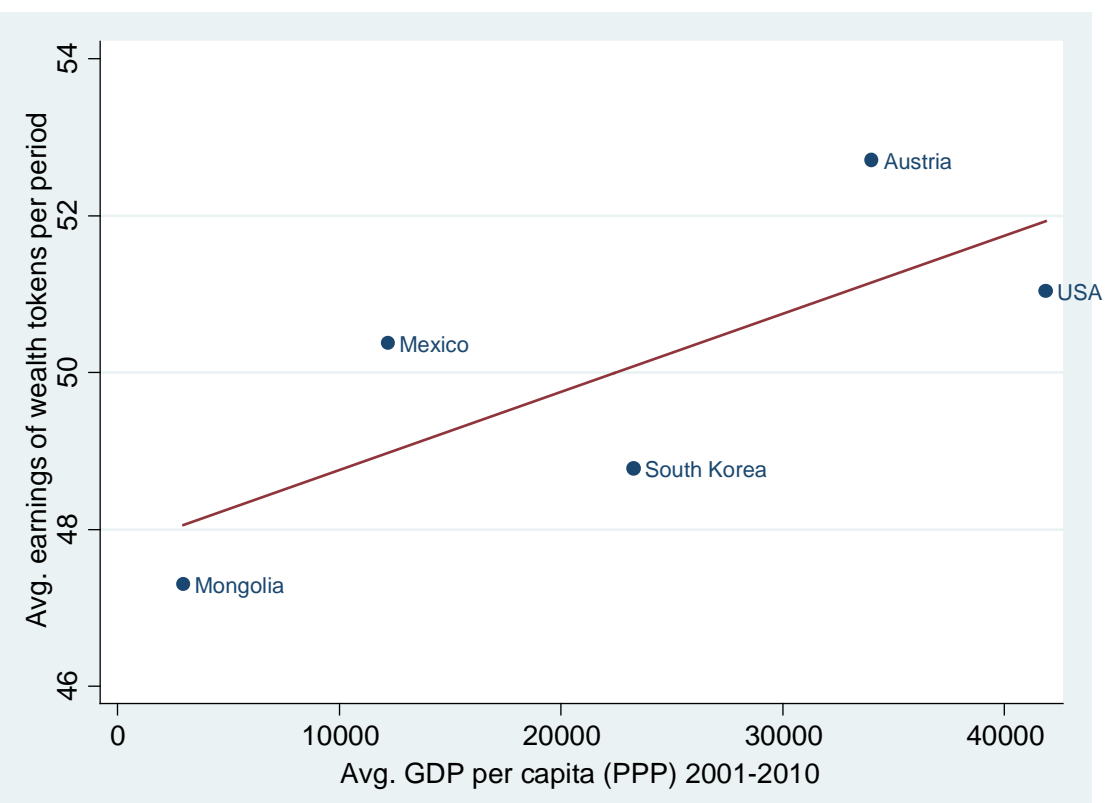

Figure 8: Perceived lack of safety, trust, and abstaining from theft in period 1
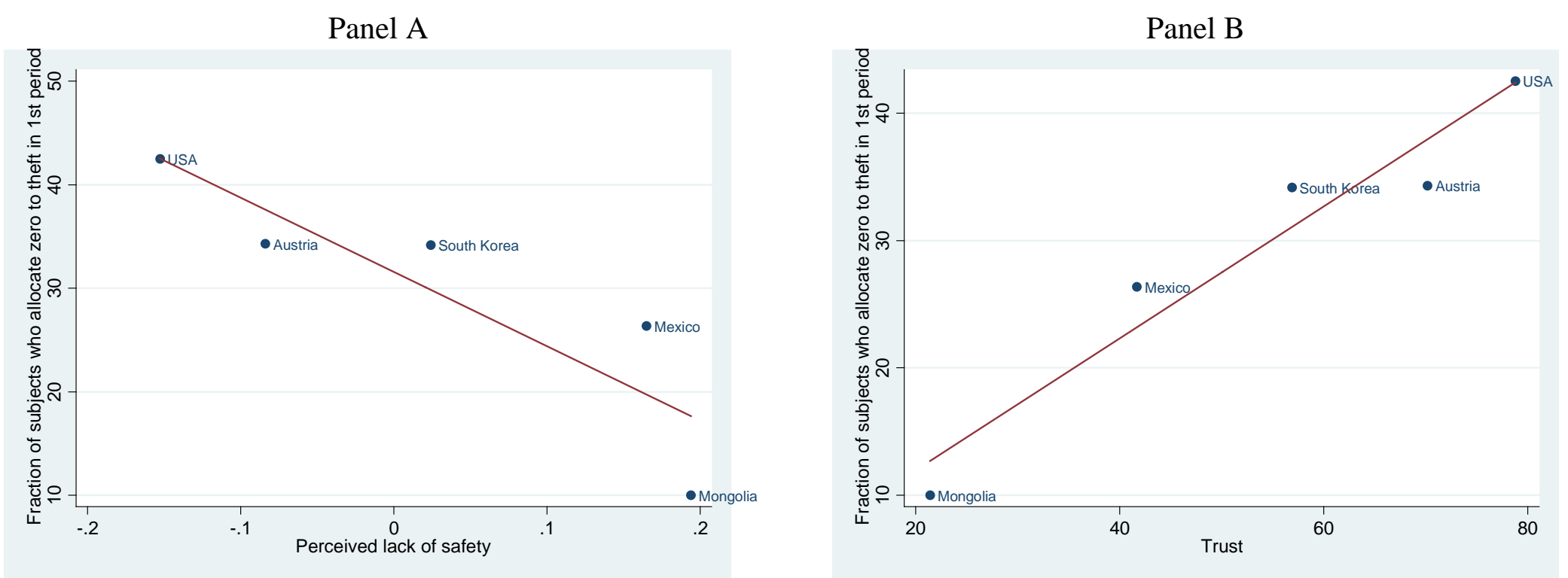


\section{Figure 9: Trust and production}

All periods

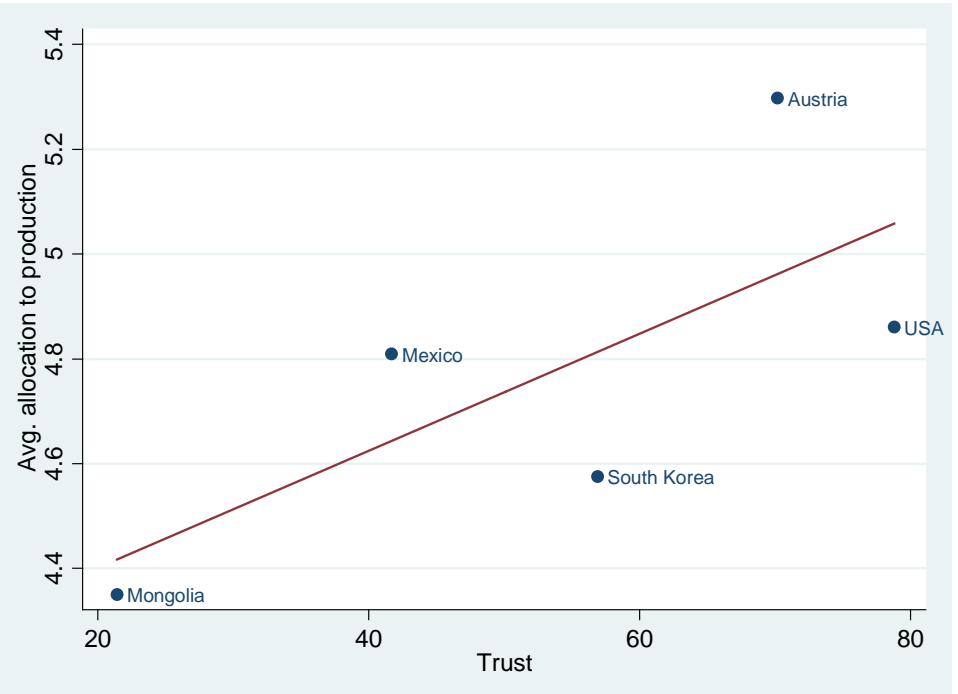

1st period

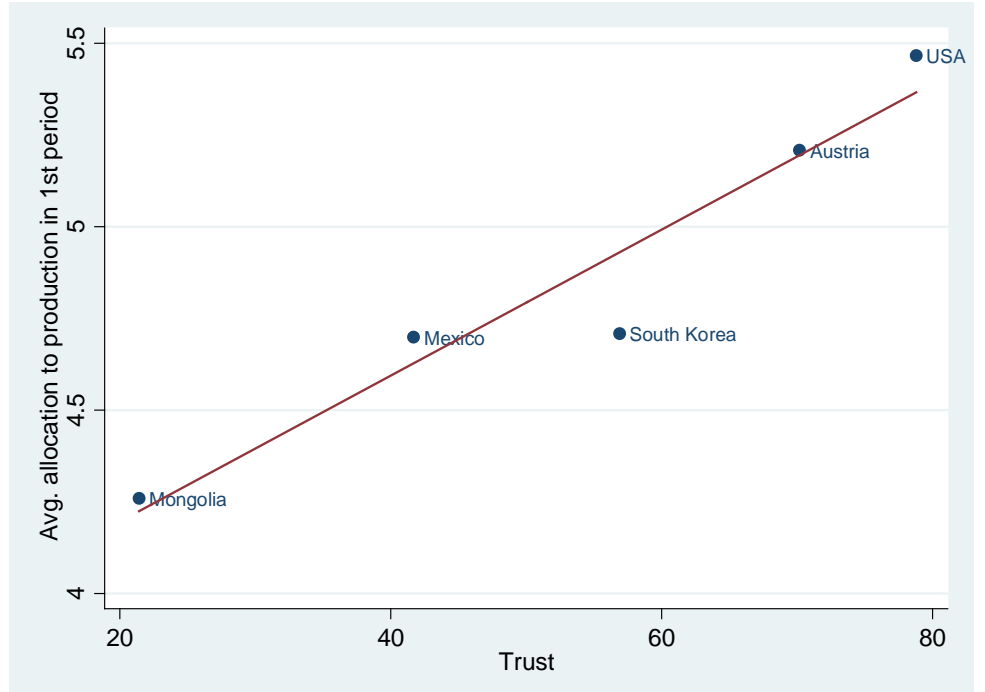

Figure 10: Perceived lack of safety and private protection

All periods

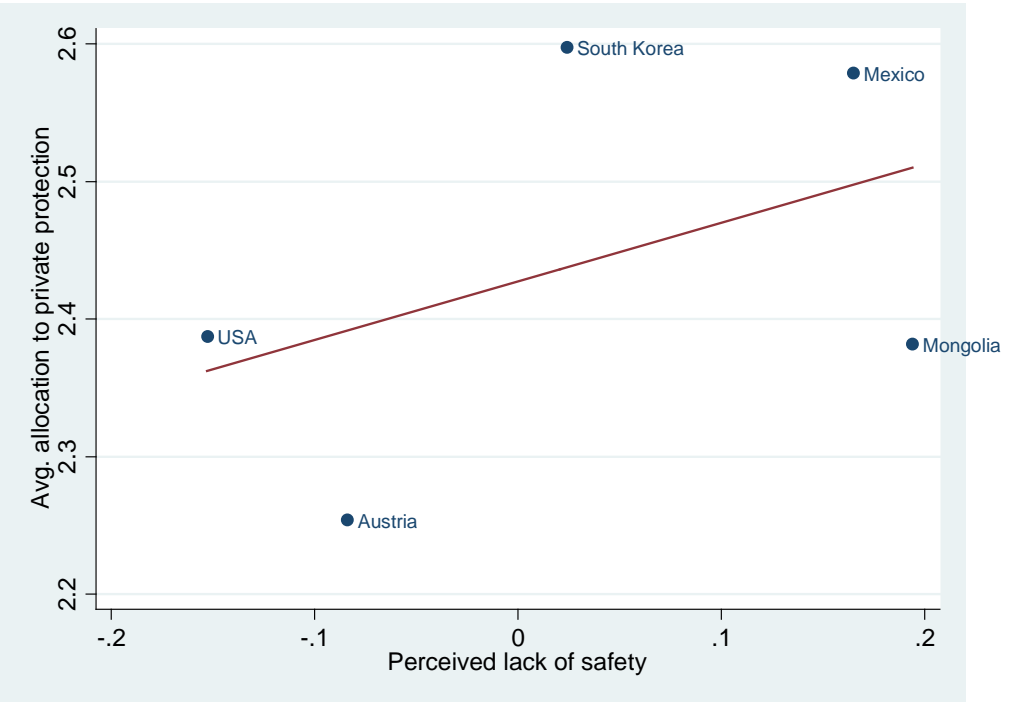

1st period

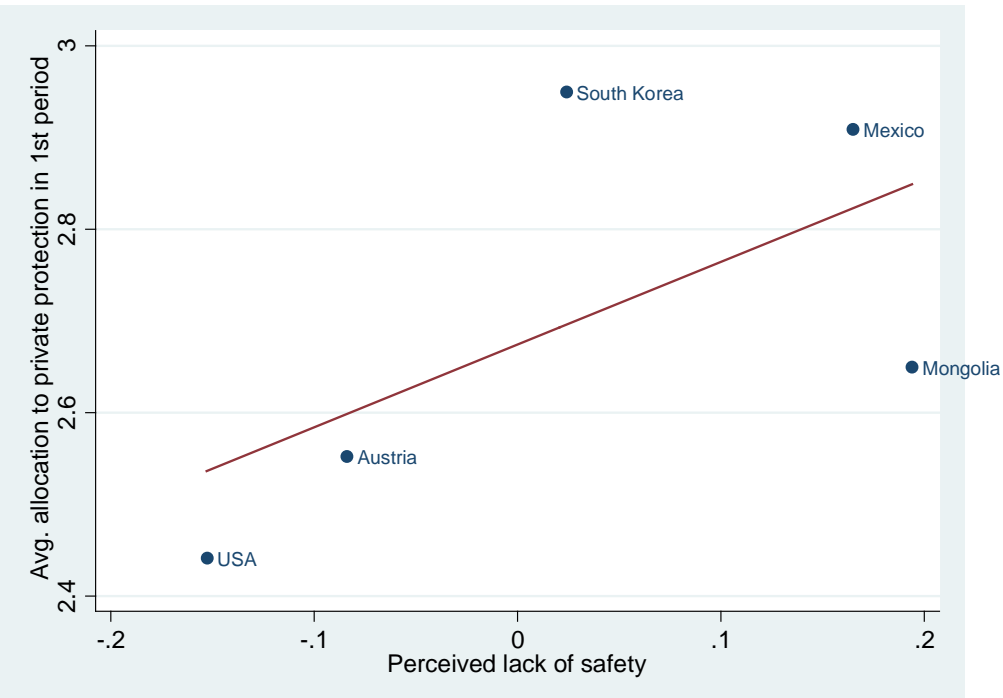


Figure 11: Perceived lack of safety and collective protection

All periods

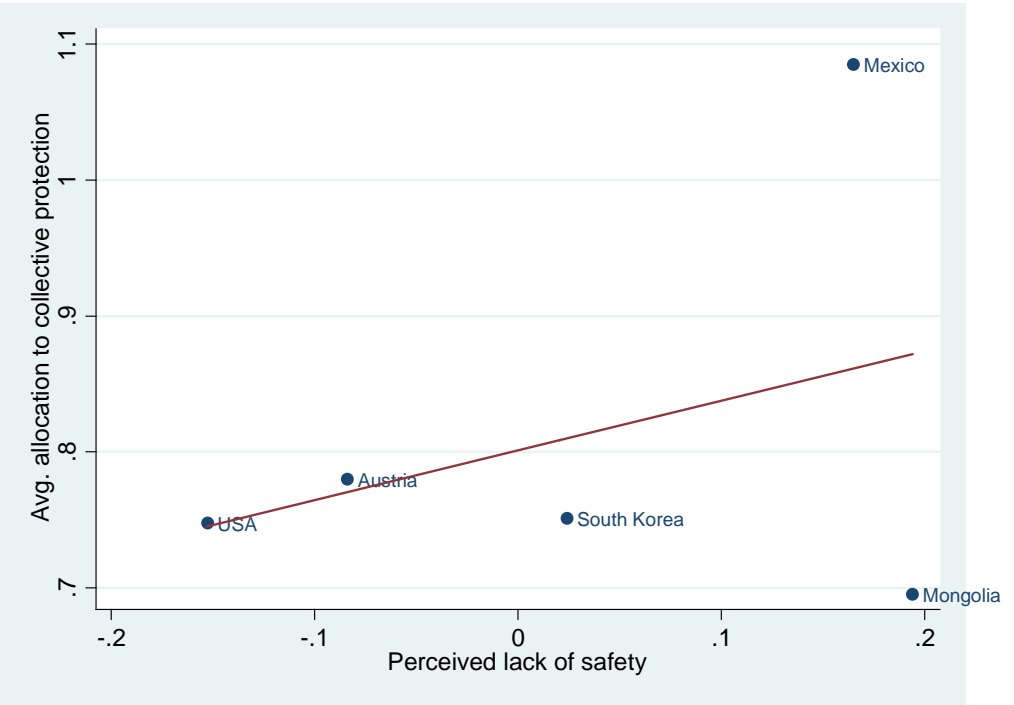

1st period

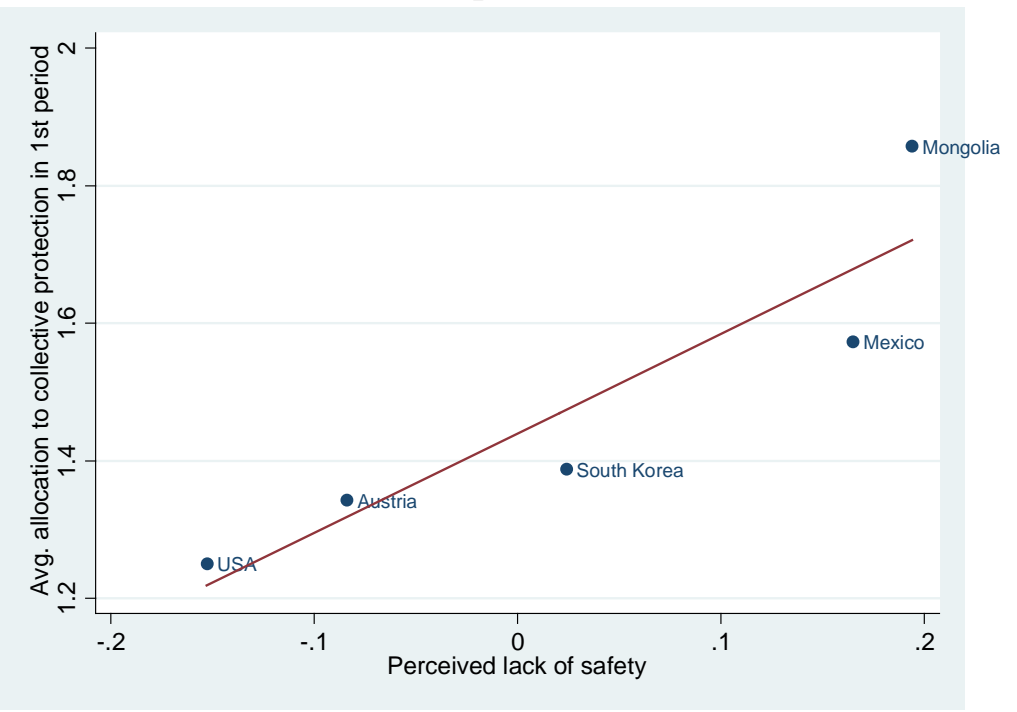


Figure 12: Governance and share of individual votes for the mandatory scheme

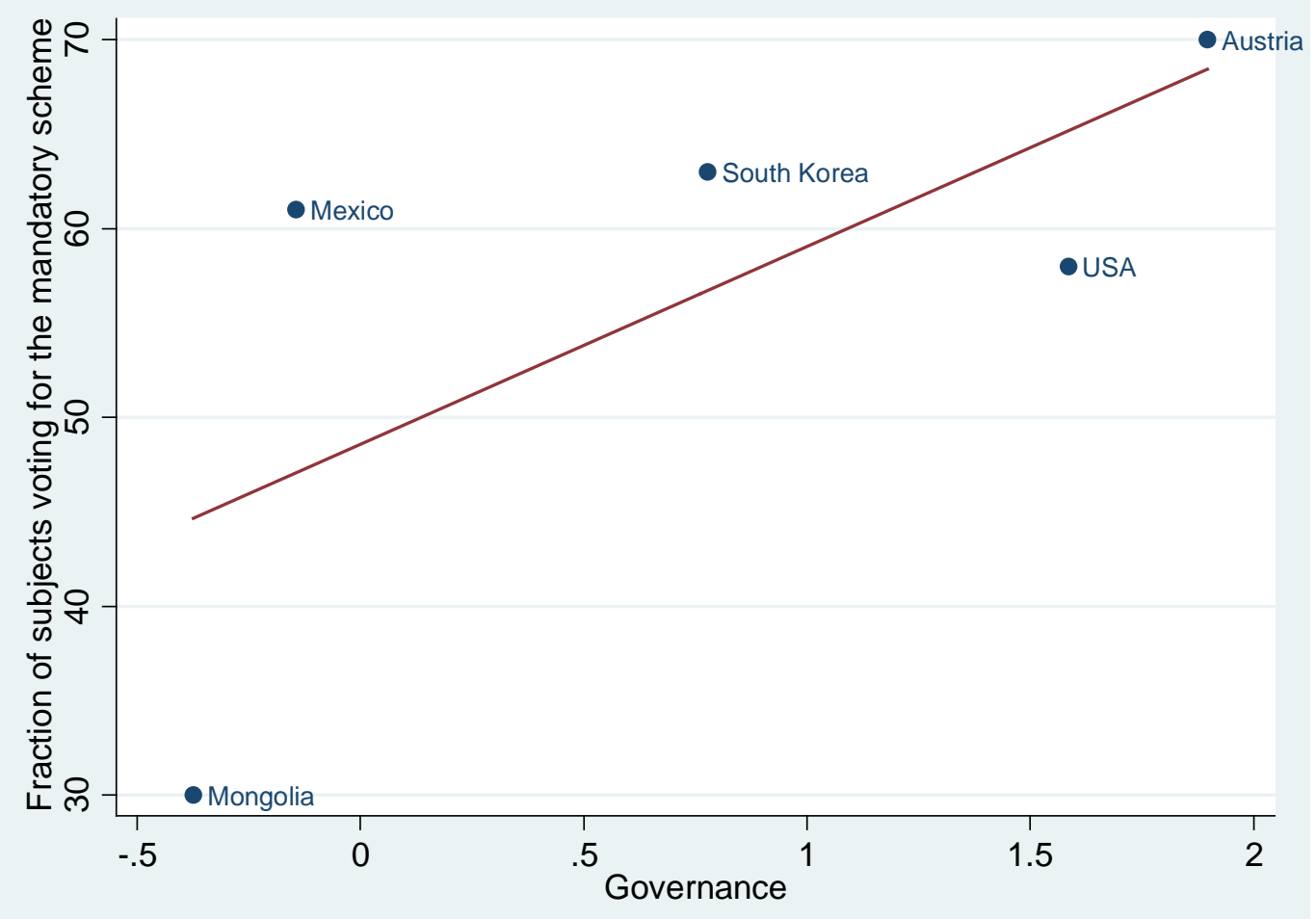

Table 1: Wealth production schedule

\begin{tabular}{c|c}
\hline \hline \# Effort Tokens & \# Wealth Tokens Produced \\
\hline 1 & 15 \\
2 & 28 \\
3 & 39 \\
4 & 48 \\
5 & 55 \\
6 & 60 \\
7 & 64 \\
8 & 67 \\
9 & 69 \\
10 & 70 \\
\hline \hline
\end{tabular}


Table 2: Treatments and group (subject) numbers by site

\begin{tabular}{|c|c|c|c|c|c|c|c|}
\hline \multirow[b]{2}{*}{ Treatment } & \multirow[b]{2}{*}{ Description } & \multicolumn{6}{|c|}{ Number of Groups (Subjects) } \\
\hline & & Austria & Mexico & Mongolia & $\begin{array}{c}\text { South } \\
\text { Korea }\end{array}$ & U.S. & Total \\
\hline $\begin{array}{c}\text { NCP } \\
\text { (No } \\
\text { Collective } \\
\text { Protection) }\end{array}$ & $\begin{array}{l}\text { Identical period structure } \\
\text { with simultaneous } \\
\text { allocation of } \\
\text { endowments among } \\
\text { three activities only. }\end{array}$ & $\begin{array}{c}7 \\
(35)\end{array}$ & $\begin{array}{c}7 \\
(35)\end{array}$ & $\begin{array}{c}6 \\
(30)\end{array}$ & $\begin{array}{c}8 \\
(40)\end{array}$ & $\begin{array}{c}8 \\
(40)\end{array}$ & $\begin{array}{c}36 \\
(180)\end{array}$ \\
\hline $\begin{array}{c}\text { VCP } \\
\text { (Voluntary } \\
\text { Collective } \\
\text { Protection) }\end{array}$ & $\begin{array}{l}\text { Identical period structure } \\
\text { with stage } 1 \text { allocations } \\
\text { to collective protection, } \\
\text { stage } 2 \text { allocations to } \\
\text { remaining three } \\
\text { activities. }\end{array}$ & $\begin{array}{c}7 \\
(35)\end{array}$ & $\begin{array}{c}8 \\
(40)\end{array}$ & $\begin{array}{c}6 \\
(30)\end{array}$ & $\begin{array}{c}8 \\
(40)\end{array}$ & $\begin{array}{c}8 \\
(40)\end{array}$ & $\begin{array}{c}37 \\
(185)\end{array}$ \\
\hline VOTE & $\begin{array}{l}\text { Phase } 1 \text { like NCP, then } \\
\text { vote on independent } \\
\text { versus mandatory voted } \\
\text { allocations to collective } \\
\text { protection at beginning } \\
\text { of each of phases 2-6. }\end{array}$ & $\begin{array}{c}7 \\
(35)\end{array}$ & $\begin{array}{c}7 \\
(35)\end{array}$ & $\begin{array}{c}8 \\
(40)\end{array}$ & $\begin{array}{c}8 \\
(40)\end{array}$ & $\begin{array}{c}8 \\
(40)\end{array}$ & $\begin{array}{c}38 \\
(190)\end{array}$ \\
\hline Total & & $\begin{array}{c}21 \\
(105)\end{array}$ & $\begin{array}{c}22 \\
(110)\end{array}$ & $\begin{array}{c}20 \\
(100)\end{array}$ & $\begin{array}{c}24 \\
(120)\end{array}$ & $\begin{array}{c}24 \\
(120)\end{array}$ & $\begin{array}{c}111 \\
\text { (555) }\end{array}$ \\
\hline
\end{tabular}


Table 3: Predicted and actual average behaviors and outcomes by treatment

\begin{tabular}{l|c|c|c|c|c|c|c|c|c|c|c|c}
\hline & \multicolumn{2}{|c|}{ Production } & \multicolumn{2}{|c|}{ Theft } & \multicolumn{2}{c|}{$\begin{array}{c}\text { Private } \\
\text { Protection }\end{array}$} & \multicolumn{2}{c|}{$\begin{array}{c}\text { Collective } \\
\text { Protection }\end{array}$} & \multicolumn{3}{c}{$\begin{array}{c}\text { Earnings } \\
\%\end{array}$} & \multicolumn{2}{c}{$\begin{array}{c}\text { Max. Efficiency } \\
\text { Gain }\end{array}$} \\
\hline NCP & $\mathbf{3}$ & 4.29 & $\mathbf{7}$ & 2.85 & $\mathbf{0}$ & 2.87 & n.a. & n.a. & 39 & 46.64 & $\mathbf{0 \%}$ & $24.6 \%$ \\
\hline VCP & $\mathbf{3}$ & 4.83 & $\mathbf{7}$ & 2.01 & $\mathbf{0}$ & 2.74 & $\mathbf{0}$ & 0.43 & 39 & 50.35 & $\mathbf{0 \%}$ & $36.6 \%$ \\
\hline VOTE & $\mathbf{7}$ & 5.32 & $\mathbf{0}$ or $\mathbf{1}$ & 1.85 & $\mathbf{0}$ & 1.57 & $\mathbf{2}$ or $\mathbf{3}$ & 1.26 & $\mathbf{6 4}$ & 53.89 & $\mathbf{8 0 . 6 \%}$ & $48.0 \%$ \\
\hline Voluntary Scheme & $\mathbf{3}$ & 4.45 & $\mathbf{7}$ & 2.82 & $\mathbf{0}$ & 2.35 & $\mathbf{0}$ & 0.39 & $\mathbf{3 9}$ & 48.21 & $\mathbf{0 \%}$ & $29.7 \%$ \\
\hline Mandatory Scheme & $\mathbf{7}$ & 5.82 & $\mathbf{0}$ or $\mathbf{1}$ & 1.29 & $\mathbf{0}$ & 1.13 & $\mathbf{2}$ or $\mathbf{3}$ & 1.76 & $\mathbf{6 4}$ & 57.12 & $\mathbf{8 0 . 6 \%}$ & $58.5 \%$ \\
\hline \hline
\end{tabular}

Bold entries are predicted values assuming rational self-interested decision-makers with common knowledge of type. For the VOTE treatment, entries refer to phases 2-6 when choice between two methods of contributing to collective protection is available. Earnings are assumed equal to 64 regardless of whether 2 or 3 tokens are mandated to collective protection assuming that slight risk-aversion leads subjects to allocate a seventh token to production rather than theft despite an equal expected return. Percentage of maximum efficiency gain is the fraction of the 31 wealth token difference between earnings predicted in conditions without mandatory collective protection (39) and socially optimal earnings (70). 
Table 4: p-values of Mann-Whitney tests of difference in allocations across treatments

\begin{tabular}{lcc}
\hline \hline & VCP & VOTE \\
\cline { 2 - 3 } Collective protection & - & $<.01$ \\
VCP & & \\
Production & $<.01$ & $<.01$ \\
NCP & - & $<.01$ \\
VCP & & \\
& & \\
Private protection & 0.33 & $<.01$ \\
NCP & - & $<.01$ \\
VCP & & \\
Theft & $<.01$ & $<.01$ \\
NCP & - & 0.28 \\
VCP & & \\
Earnings per period & $<.01$ & $<.01$ \\
NCP & - & $<.01$ \\
VCP & & \\
\hline \hline
\end{tabular}

For the VOTE treatment, only results from phases 2-6, when choice between two methods of contributing to collective protection is available, are taken into account. 
Table 5: Kruskal-Wallis tests of difference in allocations across countries

\begin{tabular}{|c|c|c|}
\hline & $\chi^{2}(4)$ adjusted for ties & $p$-value \\
\hline \multicolumn{3}{|l|}{ Panel A: NCP } \\
\hline Production & 12.57 & 0.01 \\
\hline Private protection & 2.43 & 0.66 \\
\hline Theft & 4.63 & 0.33 \\
\hline Earnings per period & 12.10 & 0.02 \\
\hline \multicolumn{3}{|l|}{ Panel B: VCP } \\
\hline Collective protection & 5.32 & 0.26 \\
\hline Production & 8.44 & 0.08 \\
\hline Private protection & 6.29 & 0.18 \\
\hline Theft & 7.20 & 0.13 \\
\hline Earnings per period & 5.46 & 0.24 \\
\hline \multicolumn{3}{|l|}{ Panel C: VOTE (phases 2-6) } \\
\hline \multicolumn{3}{|l|}{ (i) Institutional preferences } \\
\hline Support for mandatory scheme & 13.69 & 0.01 \\
\hline Selection of mandatory scheme & 10.62 & 0.03 \\
\hline \multicolumn{3}{|l|}{ (ii) Under mandatory scheme } \\
\hline Support for mandatory scheme (next vote) & 4.24 & 0.37 \\
\hline Collective protection & 5.70 & 0.22 \\
\hline Production & 6.42 & 0.17 \\
\hline Private protection & 7.52 & 0.11 \\
\hline Theft & 5.20 & 0.27 \\
\hline Earnings per period & 5.67 & 0.23 \\
\hline \multicolumn{3}{|l|}{ (iii) Under independent contributions } \\
\hline Support for mandatory scheme (next vote) & 14.66 & 0.01 \\
\hline Collective protection & 9.49 & 0.05 \\
\hline Production & 1.05 & 0.90 \\
\hline Private protection & 9.56 & 0.05 \\
\hline Theft & 3.41 & 0.49 \\
\hline Earnings per period & 2.28 & 0.69 \\
\hline
\end{tabular}


Table 6: Adoption of mandatory or voluntary contribution schemes in VOTE

\begin{tabular}{lccccc}
\hline \hline & \multicolumn{4}{c}{$\begin{array}{c}\text { Number of groups adopting the mandatory scheme/Number } \\
\text { of groups adopting voluntary contribution scheme }\end{array}$} \\
\cline { 2 - 6 } & Phase 2 & Phase 3 & Phase 4 & Phase 5 & Phase 6 \\
\hline Austria & $4 / 3$ & $5 / 2$ & $6 / 1$ & $7 / 0$ & $6 / 1$ \\
Mexico & $5 / 2$ & $6 / 1$ & $6 / 1$ & $6 / 1$ & $6 / 1$ \\
Mongolia & $1 / 7$ & $4 / 4$ & $1 / 7$ & $1 / 7$ & $2 / 6$ \\
South Korea & $7 / 1$ & $6 / 2$ & $7 / 1$ & $5 / 3$ & $5 / 3$ \\
U.S.A. & $3 / 5$ & $5 / 3$ & $6 / 2$ & $5 / 3$ & $6 / 2$ \\
\hline \hline
\end{tabular}




\section{Appendix - not intended for publication}

\section{Appendix A - Measures of crime incidence, perception of safety, trust and governance}

The first two columns in Table A1 show the share of respondents who answered "yes" to each of the two questions we considered in order to gauge the frequency of property crimes in the countries where we conducted the experiments. The source of the data is the United Nations' International Crime Victims Survey (ICVS). We used information from years 2000 in the case of Mongolia ( $\mathrm{N}=944)$ and South Korea $(\mathrm{N}=2,043), 2004$ for Mexico $(\mathrm{N}=1,992)$ and the U.S. $(\mathrm{N}=2,011)$, and 2005 for Austria $(\mathrm{N}=2,004)$. The third column presents our measure for the incidence of crime, defined as the share of respondents who replied positively to either question.

\section{Table A1: Incidence of crime}

\begin{tabular}{lccc}
\hline \hline & \multicolumn{2}{c}{$\begin{array}{c}\text { Share (\%) of respondents who answered "yes" to the } \\
\text { question: }\end{array}$} \\
\cline { 2 - 4 } & $\begin{array}{l}\text { Over the past 5 years, } \\
\text { Over the past } 5 \text { years, did } \\
\text { anyone actually get into your } \\
\text { house or flat without } \\
\text { permission and steal or try to } \\
\text { steal something? }\end{array}$ & $\begin{array}{l}\text { something from you, by } \\
\text { using force, or } \\
\text { threatening you? Or did } \\
\text { anyone try to do so? }\end{array}$ & \\
Incidence of crime \\
\hline Austria & 6.14 & 2.00 & 7.88 \\
Mexico & 10.89 & 9.54 & 18.72 \\
Mongolia & 27.21 & 10.85 & 34.04 \\
South Korea & 15.02 & 1.42 & 15.91 \\
U.S.A. & 5.99 & 3.33 & 8.35 \\
\hline \hline
\end{tabular}

The first two columns in Table A2 present the shares of respondents who reported in the ICVS feeling unsafe, as judged by their perceptions of safety when walking in the dark or the chances that their homes get broken into over the course of the following year. The third column shows the composite measure of safety perceptions obtained by applying factor analysis on the previous two metrics. 
Table A2: Perceptions of safety

\begin{tabular}{|c|c|c|c|}
\hline & $\begin{array}{l}\text { Share (\%) of } \\
\text { respondents who report } \\
\text { feeling "a bit unsafe" or } \\
\text { "very unsafe" when } \\
\text { walking alone after dark }\end{array}$ & $\begin{array}{l}\text { Share (\%) of respondents } \\
\text { who reckon it is "likely" or } \\
\text { "very likely" that over the } \\
\text { next twelve months someone } \\
\text { will try to break into their } \\
\text { homes }\end{array}$ & Perception of safety \\
\hline Austria & 21.7 & 27.74 & -0.08 \\
\hline Mexico & 34.59 & 37.00 & 0.17 \\
\hline Mongolia & 53.81 & 20.87 & 0.19 \\
\hline South Korea & 21.93 & 31.03 & 0.02 \\
\hline U.S.A. & 20.07 & 14.92 & -0.15 \\
\hline
\end{tabular}

On trust, we employ data from miscellaneous attitudes surveys conducted around the world in recent years (e.g., the World Values Survey, East Asia Barometer, Latinobarómetro, the European Values Survey) on what has come to be called the "generalized trust question,” namely, "Generally speaking, would you say that most people can be trusted, or that you can't be too careful in dealing with people?” The trust index is constructed based on the formula

Trust index $=100+(\%$ Most people can be trusted $)$ - (\% Can't be too careful) . Thus, scores over 100 are observed in countries where a larger share of people trust others, whereas scores below 100 correspond to countries where a majority of people have reservations in their dealings with others. ${ }^{26}$ Table A3 shows the scores of our pool of five countries.

Table A3: Trust index

\begin{tabular}{lccc}
\hline \hline & Source & Year & Trust index \\
\hline Austria & European Values Survey & 1999 & 70.2 \\
Mexico & Latinobarómetro & 2008 & 41.7 \\
Mongolia & East Asian Barometer & 2006 & 21.4 \\
South Korea & World Values Survey & 2005 & 56.9 \\
U.S.A. & World Values Survey & 2006 & 78.8 \\
\hline \hline
\end{tabular}

${ }^{26}$ See http://www.jdsurvey.net/jds/jdsurveyMaps.jsp?Idioma=I\&SeccionTexto=0404\&NOID=104 
The Government Index was constructed from three variables-government effectiveness, rule of law, and control of corruption-included in a dataset of governance measures assembled by the World Bank. Government effectiveness is meant to capture "perceptions of the quality of public services, the quality of the civil service and the degree of its independence from political pressures, the quality of policy formulation and implementation, and the credibility of the government's commitment to such policies.” Rule of law represents "perceptions of the extent to which agents have confidence in and abide by the rules of society, and in particular the quality of contract enforcement, property rights, the police, and the courts, as well as the likelihood of crime and violence.” And control of corruption embodies "perceptions of the extent to which public power is exercised for private gain, including both petty and grand forms of corruption, as well as 'capture' of the state by elites and private interests.”27

Table A4: Governance index

\begin{tabular}{lcccc}
\hline \hline & $\begin{array}{c}\text { Government } \\
\text { effectiveness }\end{array}$ & $\begin{array}{c}\text { Rule of } \\
\text { law }\end{array}$ & $\begin{array}{c}\text { Control of } \\
\text { corruption }\end{array}$ & $\begin{array}{c}\text { Governance } \\
\text { Index }\end{array}$ \\
\hline Austria & 1.78 & 1.83 & 1.94 & 1.90 \\
Mexico & 0.17 & -0.42 & -0.20 & -0.14 \\
Mongolia & -0.46 & -0.16 & -0.42 & -0.37 \\
South & & & & 0.78 \\
Korea & 1.02 & 0.90 & 0.47 & 1.59 \\
U.S.A. & 1.60 & 1.53 & 1.53 & \\
\hline \hline
\end{tabular}

Each of these governance measures, shown in the first three columns of Table A4, is expressed in units ranging from -2.5 to 2.5, with higher values denoting better governance outcomes. We averaged each country's score in each dimension across the 2000-2009 period and computed via factor analysis the Governance Index, which appears in the last column.

\footnotetext{
${ }^{27}$ For more information on the measures, see http://info.worldbank.org/governance/wgi/index.asp
} 


\section{Appendix B - Analysis of optimal tokens for production in VOTE}

If the group mandates a contribution of 3, there will be a joint “overprovision” by a total of 2 tokens, but with only $28 \%$ chance of a theft succeeding and hence an expected gain of only 2.8 wealth tokens from each token allocated to theft, it is unambiguous that all 7 remaining tokens should be devoted to production (see again Table 1), yielding expected earnings of 64 wealth tokens per period. If the group chooses a mandatory allocation of 2 , the 10 tokens in collective protection will yield a 60\% protection level and thus an expected gain of 4 wealth tokens from a token allocated to theft, causing a risk-neutral subject to put no more than 7 tokens into production and to be indifferent between putting a seventh token into production versus putting only six into production and one into theft. Assuming riskneutrality, subjects would choose randomly between 6 versus 7 tokens in production, so expected earnings would be 62 tokens $(=0.5 \times 60+0.5 \times 64)$, making the three token requirement the better choice. Assuming subjects were slightly risk-averse, however, all would choose to put a seventh token into production given a $60 \%$ protection rate, so earnings would be 64 wealth tokens, the same as when each contributes three tokens (mandatorily) to collective protection. With even stronger risk-aversion, subjects facing $60 \%$ collective protection might even prefer putting an eighth token into production, with certain return of 3 wealth tokens, to putting one effort token into theft, with expected return of 4 wealth tokens but a $40 \%$ chance of obtaining nothing. Thus, assumptions of strong risk-aversion could lead to a preference for mandating a 2 rather than 3 token allocation to collective protection, since the number of wealth tokens each produces could be 67 under this assumption. Although the earnings outcome associated with a 2 token requirement thus ranges from 62 to 67 wealth tokens, depending on degree of risk aversion, we treat 64 as the benchmark predicted earnings under the mandatory allocations scheme, since it is achieved exactly in two plausible scenarios and is close to the unweighted average outcome of the four scenarios considered. 


\section{Appendix C - Representativeness of student subjects}

\section{C.1 Student and general population responses to survey questions}

One way to investigate whether our student subject pools are representative of the general population in their countries is to compare the survey responses they provided at the end of their experiment sessions (or in the case of the Mexican subjects, one or more weeks before those sessions ${ }^{28}$ ) with those of larger surveys, such as the World Values Survey. Two questions conducive to such comparison are one regarding self-positioning on a left-to-right political spectrum and one regarding the trustworthiness of others. We display the relevant data in Table C1. On trust, we have subject responses from three of our subject pools to a question about the likelihood of a lost wallet being returned, and for all five countries, responses to the generalized trust question drawn from the World Values Survey (WVS), East Asia Barometer (EAB) and the European Values Survey (EVS) (see Appendix A). For the three countries for which both measures are available, there is a consistent ordering, with both the highest expectation that the wallet would be returned and the highest generalized trust in the U.S., the lowest response on both in Mexico, and a middle position for Austria.

Table C1: Average survey responses by subject pool in country surveys

\begin{tabular}{|c|c|c|c|c|c|c|}
\hline \multirow{2}{*}{ Category and variable } & \multirow{2}{*}{ Description and source } & \multicolumn{5}{|c|}{ Country } \\
\hline & & Austria*** & Mexico* & Mongolia** & South Korea* & U.S.* \\
\hline \multicolumn{7}{|l|}{ Trust } \\
\hline Wallet return ${ }^{\mathrm{a}}$ & Post- or pre-experiment survey & 2.83 & 2.51 & n.a. & n.a. & 3.02 \\
\hline Generalized trust ${ }^{\mathrm{b}}$ & WVS/EAB/EVS & 36.8 & 15.6 & 10.2 & 28.2 & 39.3 \\
\hline \multirow{2}{*}{ Political Outlook ${ }^{\mathrm{c}}$} & Post- or pre-experiment survey & 1.52 & 3.23 & 1.98 & 1.76 & 2.11 \\
\hline & WVS/EAB/EVS & 2.7 & 3.1 & n.a. & 2.9 & 2.85 \\
\hline
\end{tabular}

Sources: *World Values Survey Wave 5 (2005-2008); **East Asia Barometer (2006); ***European Values Survey (1999)

${ }^{\mathrm{a}} 1=0-20 \%$; $2=21-40 \%$; 3=41-60\%; 4=61-80\%; 5=81-100\%

b \% of respondents saying "most can be trusted" to the generalized trust question

c $1=$ very liberal,..., 5=very conservative

We have data on self-reported political outlook from both our subject survey and the WVS/EVS for four countries, data for Mongolia being unavailable in the EAB. In this

\footnotetext{
${ }^{28}$ In order to minimize the danger of influencing subjects' behaviors during the experiment by asking questions about attitudes towards theft prior to their experiment session, the pre-experiment survey of ITAM students in Mexico City included more than three times the number of questions as the post-experiment surveys administered elsewhere, with questions on theft interspersed among questions on various other political and social topics.
} 
case, our own survey question wording is identical to that in the WVS and EVS. For these four countries there is consistency between the two sources insofar as Austria is the most liberal and Mexico the most conservative. The orderings for the two countries in the middle, South Korea and the U.S., differ by survey, although their WVS values are essentially the same. In the case of political outlook, the numbers suggest that with the exception of our Mexican site, the university students were more politically liberal than the general populations of their countries.

\section{C.2 Experiments with non-student subjects in Mongolia}

A different type of information about external validity comes from conducting the same experiment with a different subject pool. Batsaikhan had the opportunity to carry out sessions of the VCP and VOTE treatments with 80 subjects recruited from among a group of small-scale entrepreneurs whose business practices he was engaged in studying for other purposes. Decision-making by members of this non-student subject pool has considerable qualitative overlap with that of the student subject pools. Interestingly, the Mongolian entrepreneurs achieved 3.5\% (8.7\%) higher earnings than the Mongolian students in the VCP (VOTE) treatments, even exceeding the average earnings of student subjects in the five countries as a whole by $0.4 \%$ (1.2\%), although still earning less than the bestperforming subject pools. The finding that social cooperation is if anything somewhat greater in subject populations of older adults is a common one (see Sutter and Kocher, 2007). Another interesting finding is that entrepreneurs who are more successful in their real world business activity devoted significantly more tokens to production in the first period of the experiment than did less successful entrepreneurs. Details are in Mongoljin Batsaikhan, "Why are Some Entrepreneurs Successful? The Implications of Decisions in Lab Experiments for Business Outcomes,” (in progress). 


\section{Appendix D - Why is there lower-than-predicted theft and higher-than- predicted private protection?}

The investment in private protection was higher than predicted and this difference was in many periods sufficient to make the observed (low) levels of theft rational. But these allocations to protection remain unexplained by either payoff-maximization or riskaversion. We briefly explore three alternative explanations: loss aversion, moral reservations, and asymmetric protective motives.

\section{D.1 Loss aversion}

In Section 2, we saw that a self-interested, rational and non-risk-loving subject would expect group members to allocate seven tokens to theft and three to production each period. Relative to that choice, withdrawing a token from theft reduces the decision-maker's earnings by ten tokens and devoting that token instead to private protection increases expected earnings by maintaining possession of seven tokens that would otherwise be forfeited. A subject might prefer this alternative if she values seven tokens that are in her existing accumulation more than she values ten tokens she could steal from another's. Possible reasons for such a preference are loss aversion and the devaluation of stolen tokens by moral taint.

Loss aversion can be modeled formally by assuming that subject $i$ seeks to maximize the sum of utility from final wealth and gain-loss utility taking the form used by Koszegi and Rabin (2006):

$$
\mu(x)= \begin{cases}\eta x & \text { if } x>0 \\ \eta \lambda x & \text { if } x<0\end{cases}
$$

where $\eta$ is the weight placed on gain-loss utility, $x$ are the gains $(x>0)$ or losses $(x<0)$, and $\lambda>1$ is the coefficient of loss aversion. Then, treating wealth tokens accumulated through theft as gains and wealth tokens lost to theft as losses, it can be shown that the utility for subject $i$ is higher under profile $\left(m_{i}, T_{i}-1, p_{i}+1\right)$ than under profile $\left(m_{i}, T_{i}, p_{i}\right)$ as long as $\lambda>10\left(1-0.1 p_{i}\right) / T_{i}$. For example, if all members of a group are devoting four tokens to theft and two to private protection, it follows from the formula that subject $i$ is better off allocating a third token to protection as long as $\lambda>2$. A $\lambda$-value of two may be plausible, since Tversky and Kahneman (1992) provide a median estimate of 2.25 for $\lambda$. 


\section{D.2 Moral reservations}

Reluctance to steal on moral grounds is another factor that might plausibly account for lower-than-predicted allocations to theft. It is noteworthy that in the first period of the NCP treatment, where subjects determined their allocations to theft and private protection in the complete absence of signals of others' plans, roughly one quarter of subjects did not allocate any token to theft. Since allocations to private protection large enough to make even a one-token allocation to theft unprofitable were only a remote possibility, this much

forbearance from theft probably indicates that substantial numbers of subjects were reluctant to steal before being given the "moral green light" to do so that would come from others' stealing.

Although substantial allocations to private protection may explain lower-thanexpected theft levels, some causation could run in the opposite direction. We conducted the following exercise to check whether private protection could have been motivated in this way.

Table D1: Allocations to private protection

\begin{tabular}{|c|c|c|c|c|c|c|c|}
\hline & \multicolumn{2}{|c|}{ NCP } & \multicolumn{3}{|c|}{ VCP } & \multicolumn{2}{|c|}{ NCP \& VCP } \\
\hline & $(1)$ & $(2)$ & (3) & $(4)$ & $(5)$ & $(6)$ & $(7)$ \\
\hline Optimal allocation & $\begin{array}{c}0.794^{* * * *} \\
(0.077)\end{array}$ & $\begin{array}{c}0.780^{* * * *} \\
(0.074)\end{array}$ & $\begin{array}{c}0.772^{* * * *} \\
(0.083)\end{array}$ & $\begin{array}{c}0.760^{* * *} \\
(0.081)\end{array}$ & $\begin{array}{c}0.744^{* * * *} \\
(0.082)\end{array}$ & $\begin{array}{c}0.781^{* * * *} \\
(0.057)\end{array}$ & $\begin{array}{c}0.770 * * * \\
(0.055)\end{array}$ \\
\hline Loss through theft in t-1 & & $\begin{array}{c}-0.002 * \\
(0.001)\end{array}$ & & $\begin{array}{c}0.001 \\
(0.002)\end{array}$ & $\begin{array}{c}0.001 \\
(0.002)\end{array}$ & & $\begin{array}{l}-0.001 \\
(0.001)\end{array}$ \\
\hline Loss through theft in t-2 & & $\begin{array}{c}0.001 \\
(0.001)\end{array}$ & & $\begin{array}{c}0.003^{* *} \\
(0.001)\end{array}$ & $\begin{array}{c}0.003^{* *} \\
(0.001)\end{array}$ & & $\begin{array}{c}0.001 \\
(0.001)\end{array}$ \\
\hline Accumulated profit thru t-1 & & $\begin{array}{c}0.000 \\
(0.001)\end{array}$ & & $\begin{array}{c}0.000 \\
(0.001)\end{array}$ & $\begin{array}{c}0.000 \\
(0.001)\end{array}$ & & $\begin{array}{c}0.000 \\
(0.001)\end{array}$ \\
\hline Collective Protection & & & & & $\begin{array}{c}-1.335^{*} \\
(0.740)\end{array}$ & & \\
\hline Gains from theft in $\mathrm{t}-1$ & & $\begin{array}{c}0.010^{* * * *} \\
(0.002)\end{array}$ & & $\begin{array}{c}0.010^{* * *} \\
(0.003)\end{array}$ & $\begin{array}{c}0.009 * * * \\
(0.003)\end{array}$ & & $\begin{array}{c}0.009 * * * \\
(0.002)\end{array}$ \\
\hline Accumulated gains from theft thru t-1 & & $\begin{array}{l}0.001^{*} \\
(0.000)\end{array}$ & & $\begin{array}{c}0.000 \\
(0.001)\end{array}$ & $\begin{array}{c}0.000 \\
(0.001)\end{array}$ & & $\begin{array}{l}0.001^{*} \\
(0.000)\end{array}$ \\
\hline Constant & $\begin{array}{c}2.244^{* * * *} \\
\quad(0.207)\end{array}$ & $\begin{array}{l}1.687 * \\
(0.933)\end{array}$ & $\begin{array}{c}1.741^{* * *} \\
(0.255)\end{array}$ & $\begin{array}{c}1.444 \\
-(1.369)\end{array}$ & $\begin{array}{l}1.704 \\
(1.349)\end{array}$ & $\begin{array}{c}2.657 * * * \\
(0.089)\end{array}$ & $\begin{array}{c}2.576 * * * \\
(0.155)\end{array}$ \\
\hline Individual FE & $\mathrm{Y}$ & $\mathrm{Y}$ & $\mathrm{Y}$ & $\mathrm{Y}$ & $\mathrm{Y}$ & $\mathrm{Y}$ & $\mathrm{Y}$ \\
\hline Round FE & $\mathrm{Y}$ & $\mathrm{Y}$ & $\mathrm{Y}$ & $\mathrm{Y}$ & $\mathrm{Y}$ & $\mathrm{Y}$ & $\mathrm{Y}$ \\
\hline Observations & 3,960 & 3,960 & 4,070 & 4,070 & 4,070 & 8,030 & 8,030 \\
\hline Within R-squared & 0.216 & 0.234 & 0.134 & 0.146 & 0.149 & 0.167 & 0.18 \\
\hline
\end{tabular}


Assuming that each observed allocation of less than seven tokens to theft reflects the decision-maker's operative moral constraint, we calculated the individual's expected earnings-maximizing allocation to private protection by individual and period in the NCP and VCP treatments on the (strong) assumption that he or she correctly anticipated the average amount of theft in which others would engage in each period (presumably based on previous observations). ${ }^{29}$ We then estimated equations in which this "optimal allocation to private protection” is included in a regression model of individual period-specific expenditure on private protection that also includes individual and period fixed effects. The results presented in columns (1), (3) and (6) of Table D1 suggests that our measure of optimal allocations to private protection is a strong predictor of actual allocations to private protection. The evidence is robust to the inclusion of additional control variables capturing the time-varying performances of subjects, as shown in the rest of the table.

\section{D.3 Asymmetric protective motives}

Our third explanatory factor, asymmetric protective motives, refers to anticipation of retaliation after own engagement in theft. Whereas so far we assumed theft tokens to be directed randomly (and thus distributed equally among other group members in expectation), one could argue that theft attempts against, say, subject $i$, could have been prompted by $i$ 's successful stealing in the preceding period. Assuming that $i$ anticipates this, she may find that the returns to investing a token in private protection are greater than the expected returns to theft (especially when some protection by other group members is in place), thereby making higher-than-predicted private protection more likely. Columns (2), (4), (5) and (7) of Table D1 present evidence of a significant positive correlation between stealing in the previous period and allocations to private protection in the current one.

Although both our gauge of optimal allocations to protection and asymmetric protective motives turn out to be relevant predictors of the actual allocations to private protection, our calculations show that they explain no more than one quarter of the overall average level of those allocations.

\footnotetext{
${ }^{29}$ Calculations done for the VCP treatment deduct the individual's allocation (if any) to collective protection to determine that number of tokens available for production or private protection. Estimates assuming all tokens not used for theft to be available for either production or private protection give essentially the same results, since allocations to collective protection are usually small.
} 


\section{Appendix References}

Koszegi, Botond and Matthew Rabin, 2006, “A Model of Reference-Dependent Preferences,” Quarterly Journal of Economics, 121: 1133-1166.

Sutter, Matthias and Martin Kocher, 2007, "Trust and Trustworthiness across Different Age Groups," Games and Economic Behavior, 29: 364-382.

Tversky, Amos and Daniel Kahneman, 1992, “Advances in Prospect Theory: Cumulative Representation of Uncertainty,” Journal of Risk and Uncertainty, 5: 297-323. 


\section{Appendix E - Instructions and practice scripts ${ }^{30}$}

\section{E.1 NCP}

\section{Instructions}

\section{General Information}

This is an experiment aimed at studying decision-making while interacting with other individuals. During the experiment, you will be earning money in the form of wealth tokens . At the end of the experiment you will be paid in cash in real dollars $(1$ wealth token $=1.4 థ)$. The amount you will earn will depend on your and others' decisions. Please read and listen carefully to make sure you understand the decision process. At the end of the instructions you will have a chance to ask questions. The experiment will conclude with a brief questionnaire.

\section{Your Group}

At the beginning of the experiment you will be randomly assigned to a group consisting of yourself and four others. Each member of the group will be randomly assigned a subject number (denoted Sub 0, Sub 1,..., Sub 4) which remains fixed throughout the experiment. You will interact exclusively with the people in your group of five throughout the entire experiment. All decisions are made anonymously, so no participant knows the identities of the other decision makers, nor will you ever be informed who was in your group. Payments are anonymous and will be made in cash at the end of the session.

\section{Experiment Structure}

The experiment consists of 24 rounds, organized in 6 sets of 4 rounds. Between each set of four rounds, there will be a brief pause. In total, we expect the experiment to last no more than two hours, including these instructions and practice rounds.

\section{Communication and questions}

Communication is not allowed at any time during the experiment. If you have any questions, please raise your hand and we will come to assist you. Do not hesitate to call on us.

\section{Other kinds of tokens}

During the experiment, you will have the chance to use two types of tokens. Only wealth tokens will be converted into cash at the end of the experiment. Effort tokens will also play a part, but they only have value insofar as they help you to earn or to conserve wealth tokens.

\section{$\underline{\text { Instructions }}$}

At the beginning of the first round, each member of the group (yourself included) will be endowed with 100 wealth tokens . Each round, each of you will receive 10 effort tokens money value, but they can be used to help you earn or conserve wealth tokens.

In every round, you have to allocate your effort tokens among three alternatives:

\footnotetext{
${ }^{30}$ Instructions in German, Korean, Mongolian and Spanish are available from the authors upon request.
} 
* Produce new wealth tokens 望国.

The table on the right shows the relation between effort tokens (the input) and wealth tokens (the output). For instance, if you allocate 5 effort tokens to production, you produce 55 wealth tokens which are added to your accumulation.

\begin{tabular}{|c|c|}
\hline $\begin{array}{c}\text { \# Effort } \\
\text { Tokens }\end{array}$ & $\begin{array}{c}\text { \# Wealth Tokens } \\
\text { Produced }\end{array}$ \\
\hline 1 & 15 \\
\hline 2 & 28 \\
\hline 3 & 39 \\
\hline 4 & 48 \\
\hline 5 & 55 \\
\hline 6 & 60 \\
\hline 7 & 64 \\
\hline 8 & 67 \\
\hline 9 & 69 \\
\hline 10 & 70 \\
\hline
\end{tabular}

* Steal others' wealth tokens

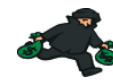
member(s) of the group, such that for every effort token you direct to stealing from, say, member 2, you will have the chance to steal 10 wealth tokens from him/her. The likelihood that your theft attempts succeed depends upon the other member's total degree of security, as described below.

* Protect your own wealth tokens from being stolen

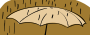
protection, the probability that you will keep your wealth tokens in the event that someone attempts to steal them rises by 10 percentage points. For example, if you put 4 effort tokens into protection, the likelihood that an attempt to steal wealth tokens from you will fail becomes 4 X $10=40 \%$ (in other words, the likelihood that the attempted theft succeeds is only 60\%). The example below illustrates the stealing mechanism as well as the determination of chances.

Example: Member 2 puts 3 effort tokens into protection and member 3 puts 1 effort token into protection. Hence, member 2's degree of protection is 3 X $10=30 \%$, while 3's level of protection is 1 X $10=10 \%$. If you direct 2 effort tokens to an attempt to steal from member 2 and 1 effort token to attempting to steal from member 3, 20 of 2's wealth tokens and/or 10 of 3's wealth tokens may be transferred to you. The likelihood of your theft from 2 succeeding is $100-30=70 \%$, and the likelihood of your theft from 3 succeeding is 100 $-10=90 \%$. The computer will ultimately determine according to the aforementioned probability of $70 \%$ whether 0 or 20 wealth tokens are transferred to you from member 2 (note: there's a $70 \%$ chance of 20 tokens being transferred, a 30\% chance of 0 tokens being transferred, and no chance of an intermediate amount being transferred). Likewise, the computer will independently decide using the probability $90 \%$ whether 0 or 10 wealth tokens are transferred to you from member 3. If a theft is successful, the wealth tokens are deducted from 2's and/or 3's accumulation and are added to yours.

Exception: If the total number of wealth tokens that other members would successfully steal from a particular group member, say member 2, exceeds 2's existing accumulation, then the computer will adjust the size of the transfers, since member 2 cannot end up with a negative number of wealth tokens. For example, suppose members 0, 1, 3 and 4 each direct 3 effort tokens to attempting to steal from Member 2, and that none of the theft attempts is prevented by the action of Member 2's degree of protection, so that a total of $3 \times 10 \times 4=$ 120 wealth tokens would be taken from member 2 . And suppose that member 2 has only 100 wealth tokens at this point. Then members $0,1,3$ and 4 would each receive only $100 / 4=25$ rather than 30 wealth tokens. The decision of each to direct 3 effort tokens against member 2 is nevertheless irrevocable; each would have spent 3 effort tokens, though gaining only 25 rather than 30 wealth tokens from it.

At the end of each round, the total number of wealth tokens will be computed according to the following formula:

$$
\begin{aligned}
\text { Wealth tokens }= & \text { Wealth tokens held at the beginning of the round } \\
& + \text { New wealth tokens produced } \\
& + \text { Wealth tokens you stole from other members } \\
& - \text { Wealth tokens other members stole from you }
\end{aligned}
$$


At the end of each round you will learn the statistics of your performance in that round as well as the cumulative statistics through that round. That is, you will find out: (i) the number of wealth tokens produced; (ii) the total number of wealth tokens you sought to steal from others and the number of wealth tokens that you successfully stole; (iii) the number of wealth tokens other group members sought to steal from you and the number of wealth tokens they successfully stole. (Note that the information on (iii) is given as an aggregate; you won't be told which particular group members attempted or succeeded to steal from you.) These amounts will be added/subtracted from the number of wealth tokens that you started the round with, according to the formula described above.

You will also learn about the total accumulation of wealth tokens in the hands of each other group member through that round, and the number of wealth tokens that each group member has thus far obtained by production, the number each has thus far obtained by stealing from others, and the number each has thus far lost by means of theft. This information will be available to you anytime in the following round as you make your allocation decisions.

\section{Payoffs}

Your earnings from this experiment will be the $\$ 5$ that is guaranteed to you simply for participating, plus $1.4 \$$ for every wealth token that you have accumulated by the end of the 24 rounds. Notice that your earnings do not depend on how much you accumulate in comparison to others, only on how much you accumulate.

To make sure that you understand how the different choices operate in the experiment, we'll now provide some examples.

\section{Examples of protection possibilities}

Example 1: Member 1 allocates 5 effort tokens to protection, member 2 allocates 3 effort tokens to protection, and members 3,4 and 5 each use 1 effort token for protection. Their corresponding levels of security are $50 \%, 30 \%, 10 \%, 10 \%$ and $10 \%$, respectively.

Example 2: Group members use various numbers of effort tokens for protection; for example 6 tokens, 4 tokens, 3 tokens, 1 token, and no tokens. They achieve the corresponding levels of security: $60 \%, 40 \%, 30 \%$, $10 \%$ and $0 \%$, respectively.

\section{Examples of the use of effort tokens and payoffs}

Example 1: You begin with 100 wealth tokens and each round you use all 10 effort tokens to produce wealth tokens. No group member ever attempts to steal wealth tokens from you. You earn 70 wealth tokens each round, accumulating a total of $100+(70$ X 24) $=1780$ wealth tokens. Your earnings in dollars would be $\$ 5+$ $(1.4 \$$ X 1780 $)=\$ 29.92$

Example 2: You begin with 100 wealth tokens and each round you allocate 2 effort tokens to protection and 8 effort tokens to stealing from others. You can steal up to 80 wealth tokens, and there is an $80 \%(=100-(2 \mathrm{X}$ $10)$ ) chance that any given attempt by others to steal wealth tokens from you will succeed. Your maximum accumulation could be $100+(80 \mathrm{X} 24)=2020$ wealth tokens, but you may earn less than this, possibly much less, if others successfully steal wealth tokens from you and/or if others use effort tokens to provide some security for their accumulations. Using the maximum estimate of 2020 wealth tokens, your accumulated earnings in dollars would be $\$ 5+(1.4 \$$ X 2020 $)=\$ 33.28$

Example 3: You begin with 100 wealth tokens and each round you and others in your group use four effort tokens for production, two effort tokens for protection, and four effort tokens for stealing, assigning one token to stealing from each other group member. You produce 48 wealth tokens, and your protection level each period is $20 \%$. The other members of your group each attempt to steal 10 wealth tokens from you and succeed in $80 \%$ of attempts, hence reducing your wealth token accumulation by 4 X $10 \times 0.8=32$ wealth tokens per period, on average. Your four attempts to steal 10 wealth tokens from other members succeed on $80 \%$ of attempts, thus adding 4 X $10 \times 0.8=32$ wealth tokens to your accumulation per period, on average. Your wealth token accumulation thus rises by an average total of 48 per period, earning you a total of $100+$ $(48 \mathrm{X} 24)=1252$ wealth tokens, for earnings of $\$ 5+(1.4 \$ \mathrm{X} 1252)=\$ 22.53$ 
Example 4: You begin with 100 wealth tokens and each round you put 3 effort tokens into protection and assign the remaining 7 effort tokens to production. Suppose other members also put 3 effort tokens into protection each period. The likelihood that a theft attempt will succeed is $100-(10 \times 3)=70 \%$. Your 7 effort tokens produce 64 wealth tokens for you each round. You can accumulate up to $100+(64 \mathrm{X} 24)=$ 1636 wealth tokens, but you may earn less if others steal tokens from you. Using the maximum estimate of 1636 wealth tokens, your total earnings would be $\$ 5+(1.4 \$$ X 1636) $=\$ 27.90$.

Note that the behavior does not change across rounds in these examples, but this is just for the sake of making these illustrations easy to understand. In fact, your strategy can change over time. As can be seen, there are an almost infinite number of possible outcomes, depending on your decisions and the decisions of others in your group.

After questions are answered and we go through two practice rounds that don't affect your earnings, you will engage in the first four periods of the experiment.

Any questions?

\section{Practice Scripts}

Before the real decision-making begins, we're going to go through two practice rounds the purpose of which is to familiarize you with the way that you enter your choices on your computer screen, the order of choice, and the information you get back after each decision. The earnings shown on your screen for these practice rounds are only illustrative, reflecting decisions I'll be asking you to enter. They have no effect on your real earnings in the experiment. Also, the participants with whom you'll interact in the practice rounds are not the ones in your group for the real decision periods. Please follow our instructions as closely as possible and do not click any buttons until told to.

The first screen you'll see tells you that you and each other person in your group has 100 wealth tokens at the beginning of the experiment. Please click next.

The next screen you'll see in each round tells you the number of wealth tokens and the number of effort tokens with which you begin the round. Please click next.

The next screen is where you have to enter your allocation choices to production, protection and theft. You have to click on at least some of the boxes below the lines saying "production tokens," "protection tokens" and "theft tokens", until you finish allocating all your effort tokens.

Please use your effort tokens as follows (and do not click submit until we tell you to):

- Assign 5 effort tokens to the production of new wealth tokens and 3 to the protection of your existing wealth tokens.

- Randomly assign your remaining 2 effort tokens to stealing from other members of your group.

Before leaving this screen, please notice the following: (a) you can click on the button labeled "Stats" at the top to learn the number of wealth tokens held by the others in your group; (b) when you enter a number of production tokens, you'll see immediately below that box the number of Wealth tokens you'll produce if you stick with that choice; (c) when you enter a number of protection tokens, you'll see below that box the total level of security of your wealth token accumulation.

Before clicking on the submit button, please also notice that it is possible to reconsider and to change your allocations at any time until you hit submit. Simply delete any entry you want to change and enter a new value. Also note that you don't need to enter a value into each box. If you enter no value under production tokens, for instance, the computer will understand your production tokens choice to be 0 . The same applies to protection and theft tokens. You can always choose 0 in any case. If the number of effort tokens you use for the round does not sum to 10 in total, you will receive an error message and will have to change entries until all of your effort tokens have been used. If you are ready, click on Submit now. 
Note that if all participants haven't yet made their decisions and clicked submit, you'll see a screen saying "Waiting for Others". There is no possibility of seeing what others decide first and then making your own decision.

When everyone has submitted their decisions you'll see a "Round Performance Summary.” Please read it and raise your hand if you have any questions about this screen. When you're done, please click on Next.

The next screen gives you information about the wealth token accumulations of each member in your group. Notice that there are two boxes: (1) the upper box shows the accumulations of each group member broken up into gains and losses through production and theft through the period that just ended; (2) the lower box shows the accumulations of each group member broken up into gains and losses through production and theft in the period that just ended. Please click on Next Round.

We'll now run through a second and final practice round. Remember, the practice rounds do not count towards determining your earnings. Again, please follow our instructions for this one last practice round.

Notice that your first screen of the round tells you your updated accumulation of wealth tokens. Note that you begin every round with the same number of effort tokens, 10 . Please click next.

Again, the next screen is for indicating your allocation choices to production, protection and theft.

Notice that you can also click on the Stats button here to view again the accumulations of each group member and the break-down according to production, gains from theft and losses due to theft. If you want the stats to disappear, you can click Hide, otherwise they will go away automatically when you click submit, but you can view them again at the next decision stage.

At the second allocation screen, please allocate your effort tokens as follows:

- 6 to production,

- 1 to protection, and

- For your theft choices, please open again the Stats window. In the real experiment, you may want to use the information in that window to help you decide whom you try to steal from. For this practice round, as an illustration, please assign 2 effort tokens to whichever member of your group (excluding yourself) has the smallest accumulation of wealth tokens after Practice 1 (check the stats window). If more than one member is tied for smallest accumulation, choose one randomly to assign your effort tokens to. Finally, assign 1 effort token to whichever member of your group has the $2^{\text {nd }}$ smallest accumulation of wealth tokens.

When everyone has submitted their decisions you'll see the Round Performance Summary, as before. When you're ready, please click on Next.

Finally, as before, the next screen gives you information about the wealth token accumulations of each group member broken up into gains and losses through production and theft.

Before we begin the rounds that count toward your real earnings, please note that the time it will take to complete all 24 rounds depends on all of your rates of progress. No individual can move forward until all participants make the corresponding decisions at each stage of the process, which includes, at the end of each period, that you finish viewing your round performance summary and click "next." Please focus on the task and click the appropriate "submit" and "next" buttons as soon as you are ready to do so, so that the process can proceed for all in a timely fashion. To help make sure that we finish before _ _ _ , we'll remind you to continue if we see that progress stalls. (We can track on our monitor whether actions have been taken but not which actions they were, that information is stored only for later analysis.)

O.k.? Please begin. 


\section{E.2 VCP}

\section{Instructions}

\section{General Information}

This is an experiment aimed at studying decision-making while interacting with other individuals. During the

experiment, you will be earning money in the form of wealth tokens . At the end of the experiment you will be paid in cash in real dollars $(1$ wealth token $=1.4 \mathbb{C})$. The amount you will earn will depend on your and others' decisions. Please read and listen carefully to make sure you understand the decision process. At the end of the instructions you will have a chance to ask questions. The experiment will conclude with a brief questionnaire.

\section{Your Group}

At the beginning of the experiment you will be randomly assigned to a group consisting of yourself and four others. Each member of the group will be randomly assigned a subject number (denoted Sub 0 , Sub 1,..., Sub 4) which remains fixed throughout the experiment. You will interact exclusively with the people in your group of five throughout the entire experiment. All decisions are made anonymously, so no participant knows the identities of the other decision makers, nor will you ever be informed who was in your group. Payments are anonymous and will be made in cash at the end of the session.

\section{Experiment Structure}

The experiment consists of 24 rounds, organized in 6 sets of 4 rounds. Between each set of four rounds, there will be a brief pause. In total, we expect the experiment to last no more than two hours, including these instructions and practice rounds.

\section{Communication and questions}

Communication is not allowed at any time during the experiment. If you have any questions, please raise your hand and we will come to assist you. Do not hesitate to call on us.

\section{Other kinds of tokens}

During the experiment, you will have the chance to use two types of tokens. Only wealth tokens will be converted into cash at the end of the experiment. Effort tokens will also play a part, but they only have value insofar as they help you to earn or to conserve wealth tokens.

\section{$\underline{\text { Instructions }}$}

At the beginning of the first round, each member of the group (yourself included) will be endowed with 100 wealth tokens . Each round, each of you will receive 10 effort tokens money value, but they can be used to help you earn or conserve wealth tokens. There are three activities you can perform using your effort tokens:

- Produce more wealth tokens 然

- Steal others' wealth tokens

- Protect your own wealth tokens from being stolen in one or both of two ways: collective protection $\left(\frac{1}{6}+\frac{1}{2} a^{3}\right.$

, which adds to the security of all members' wealth tokens, and private protection which adds to the security of the wealth tokens of the person who pays for it only

We next explain the order of decision-making and provide more details about the activities of production, theft, and protection.

In every round, decisions are made in two stages: 
- Stage 1: you have to decide how many of your 10 effort tokens you contribute to collective protection whereby the wealth tokens of every member are equally protected if another member seeks to steal them. For every effort token that any member of the group puts into collective protection, the probability that you (and each person in your group) will keep your wealth tokens if someone attempts to steal them will rise by 6 percentage points on a scale of $0-100 \%$. The highest level of security that can be attained through collective protection is reached if the sum of everyone's contributions is 12 effort tokens (or more). In that case, there is a $12 \times 6=72 \%$ chance that a member's wealth tokens will remain with them in the event of an attempt to steal them. Greater contributions beyond 12 effort tokens do not increase the probability that you will keep your wealth tokens. At the end of Stage 1, you will learn the total number of effort tokens put into collective protection and the resulting degree of security at which theft is prevented, but you will not learn how many tokens each individual put into collective protection.

- Stage 2: In this stage, you have to allocate your remaining effort tokens among three alternatives: private protection, production and theft.

Private protection only. For every effort token you assign to private protection, the probability that you will keep your wealth tokens in the event that someone attempts to steal them rises by 10 percentage points, which will be added to the level of security already achieved through collective protection. For example, if collective protection is $54 \%$ (i.e., 9 effort tokens were contributed in total) and you put 4 effort tokens into private protection, the likelihood that an attempt to steal wealth tokens from you will fail increases to $54+(4 \times 10)=94 \%$ (in other words, the likelihood that the attempted theft succeeds is only 6\%). Of course, you cannot increase the likelihood of failure beyond $100 \%$, so at some point, additional effort tokens lose their effect. In our example, if you put 5 effort tokens into private protection, the $5^{\text {th }}$ effort token raises the likelihood of a theft attempt failing by $6 \%$ only, to $100 \%$, and a $6^{\text {th }}$ effort token would have no effect. Note that effort tokens put into collective protection benefit all members equally, and that everyone knows this degree of security in each round; however, private protection benefits only you, and only you know how many effort tokens you use for private protection, thereby your own total level of protection.

$\checkmark$ Production $\mathrm{Am}$ of new wealth tokens.

The table on the right shows the relation between effort tokens (the input) and wealth tokens (the output). For instance, if you allocate 5 effort tokens to production, you produce 55 wealth tokens which are added to your accumulation.

\begin{tabular}{|c|c|}
\hline $\begin{array}{c}\text { \# Effort } \\
\text { Tokens }\end{array}$ & $\begin{array}{c}\text { \# Wealth Tokens } \\
\text { Produced }\end{array}$ \\
\hline 1 & 15 \\
\hline 2 & 28 \\
\hline 3 & 39 \\
\hline 4 & 48 \\
\hline 5 & 55 \\
\hline 6 & 60 \\
\hline 7 & 64 \\
\hline 8 & 67 \\
\hline 9 & 69 \\
\hline 10 & 70 \\
\hline
\end{tabular}

$\checkmark$ Theft group with a likelihood of success that depends upon the other members' total degree of security, as already described. You can assign effort tokens to stealing from any of the other members, such that for every effort token you direct to stealing from, say, member 2, you will have the chance to steal 10 wealth tokens from him/her. The example below illustrates the stealing mechanism as well as the determination of chances.

Example: Group members put a total of 5 effort tokens into collective protection, so the degree of security provided through collective protection is $5 \times 6 \%=30 \%$. Member 2 puts 3 effort tokens into private 
protection and member 3 puts no effort tokens into private protection. Hence, 2's total degree of protection is $30+(3 \mathrm{X} 10)=60 \%$, while 3's total level of protection is $30+(0 \mathrm{X} 10)=30 \%$. If you direct 2 effort tokens to an attempt to steal from member 2 and 1 effort token to attempting to steal from member 3, 20 of 2's wealth tokens and/or 10 of 3's wealth tokens may be transferred to you. The likelihood of your theft from 2 succeeding is $100-60=40 \%$, and the likelihood of your theft from 3 succeeding is $100-30=70 \%$. The computer will ultimately determine according to the aforementioned probability of $40 \%$ whether 0 or 20 wealth tokens are transferred to you from member 2 (note: there's a $40 \%$ chance of 20 tokens being transferred, a $60 \%$ chance of 0 tokens being transferred, and no chance of an intermediate amount being transferred). Likewise, the computer will independently decide using the probability $70 \%$ whether 0 or 10 wealth tokens are transferred to you from member 3. If a theft is successful, the wealth tokens are deducted from 2's and/or 3's accumulation and are added to yours.

Exception: If the total number of wealth tokens that other members would successfully steal from a particular group member, say member 2, exceeds 2's existing accumulation, then the computer will adjust the size of the transfers, since member 2 cannot end up with a negative number of wealth tokens. For example, suppose that members $0,1,3$ and 4 each direct 3 effort tokens to attempting to steal from member 2, and that none of the theft attempts is prevented by the action of 2's degree of protection, so that a total of 3 X 10 X $4=120$ wealth tokens would be taken from member 2. And suppose that member 2 has only 100 wealth tokens at this point. Then members $0,1,3$ and 4 would each receive only $100 / 4=25$ rather than 30 wealth tokens. The decision of each to direct 3 effort tokens against member 2 is nevertheless irrevocable; each would have spent 3 effort tokens, though gaining only 25 rather than 30 wealth tokens from it.

At the end of each round, the total number of wealth tokens will be computed according to the following formula:

$$
\begin{aligned}
\text { Wealth tokens }= & \text { Wealth tokens held at the beginning of the round } \\
& + \text { New wealth tokens produced } \\
& + \text { Wealth tokens you stole from other members } \\
& - \text { Wealth tokens other members stole from you }
\end{aligned}
$$

At the end of each round you will learn the statistics of your performance in that round as well as the cumulative statistics through that round. That is, you will find out: (i) the number of wealth tokens produced; (ii) the total number of wealth tokens you sought to steal from others and the number of wealth tokens that you successfully stole; (iii) the number of wealth tokens other group members sought to steal from you and the number of wealth tokens they successfully stole. (Note that the information on (iii) is given as an aggregate; you won't be told which particular group members attempted or succeeded to steal from you.) These amounts will be added/subtracted from the number of wealth tokens that you started the round with, according to the formula described above.

You will also learn about the total accumulation of wealth tokens in the hands of each other group member through that round, and the number of wealth tokens that each group member has thus far obtained by production, the number each has thus far obtained by stealing from others, and the number each has thus far lost by means of theft. This information will be available to you anytime in the following round as you make your allocation decisions.

\section{Payoffs}

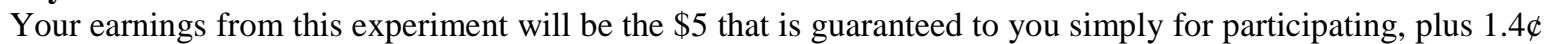
for every wealth token that you have accumulated by the end of the 24 rounds. Notice that your earnings do not depend on how much you accumulate in comparison to others, only on how much you accumulate.

To make sure that you understand how collective and private protection work in the experiment, we'll now provide some examples.

\section{Examples of protection possibilities}

Example 1: Three members each contribute two effort tokens and two members each contribute three effort tokens to collective protection, for a total of 12 , giving a protection level of $72 \%$ to everyone. Nothing is spent on private protection, so every member equally enjoys a $72 \%$ level of-protection. 
Example 2: No member contributes any effort tokens to collective protection. Each member uses three effort tokens for private protection. They each achieve a security level of $30 \%$.

Example 3: Two members each contribute two effort tokens to collective protection, while the other members contribute three, one, and zero effort tokens, respectively. In total, 8 effort tokens are contributed to collective protection, which provides a security level of $48 \%$ to everyone. Members individually use various numbers of effort tokens for private protection; for example 6 tokens, 4 tokens, 3 tokens, 1 token, and no tokens. They achieve the corresponding levels of security: $100 \%, 88 \%, 78 \%, 58 \%$ and $48 \%$, respectively.

\section{Examples of the use of effort tokens and payoffs}

Example 1: You begin with 100 wealth tokens and each round you use all 10 effort tokens to produce wealth tokens. No one ever contributes to collective protection. No group member ever attempts to steal wealth tokens from you. You earn 70 wealth tokens each round, accumulating a total of $100+(70$ X 24) $=1780$ wealth tokens. Your earnings in dollars would be $\$ 5+(1.4 \$$ X 1780 $)=\$ 29.92$

Example 2: You begin with 100 wealth tokens and each round you allocate 2 effort tokens to private protection and 8 effort tokens to stealing from others. No one ever contributes to collective protection. You can steal up to 80 wealth tokens, and there is an $80 \%$ (= $100-(2 \mathrm{X} \mathrm{10}))$ chance that any given attempt by others to steal wealth tokens from you will succeed. Your maximum accumulation could be $100+(80$ X 24) $=2020$ wealth tokens, but you may earn less than this, possibly much less, if others successfully steal wealth tokens from you and/or if others use effort tokens to provide some security for their accumulations. Using the maximum estimate of 2020 wealth tokens, your accumulated earnings in dollars would be $\$ 5+(1.4 \$$ X 2020) $=\$ 33.28$

Example 3: You begin with 100 wealth tokens and each round you and others in your group use four effort tokens for production, two effort tokens for private protection, and four effort tokens for stealing, assigning one token to stealing from each other group member. No one ever contributes to collective protection. You produce 48 wealth tokens, and your protection level each period is $20 \%$. The other members of your group each attempt to steal 10 wealth tokens from you and succeed in $80 \%$ of attempts, hence reducing your wealth token accumulation by $4 \times 10 \times 0.8=32$ wealth tokens per period, on average. Your four attempts to steal 10 wealth tokens from other members succeed on $80 \%$ of attempts, thus adding $4 \times 10 \times 0.8=32$ wealth tokens to your accumulation per period, on average. Your wealth token accumulation thus rises by an average total of 48 per period, earning you a total of $100+(48 \times 24)=1252$ wealth tokens, for earnings of $\$ 5+(1.4 \$$ $\mathrm{X} 1252)=\$ 22.53$

Example 4: You begin with 100 wealth tokens and each round you put 3 effort tokens into collective protection and assign the remaining 7 effort tokens to production. Suppose other members also put 3 effort tokens into collective protection each period. With 3 X $5=15$ tokens in collective protection, the likelihood that a theft attempt will succeed is $100-(12 \times 6)=100-72=28 \%$. Your 7 effort tokens produce 64 wealth tokens for you each round. You can accumulate up to $100+(64 \mathrm{X} 24)=1636$ wealth tokens, but you may earn less if others attempt to steal tokens from you, although in this case they have a $28 \%$ chance of success each time (versus the $80 \%$ chance of success in the previous example). Using the maximum estimate of 1636 wealth tokens, your total earnings would be $\$ 5+(1.4 \$$ X 1636) $=\$ 27.90$

Note that the behavior does not change across rounds in these examples, but this is just for the sake of making these illustrations easy to understand. In fact, your strategy can change over time. As can be seen, there are an almost infinite number of possible outcomes, depending on your decisions and the decisions of others in your group.

After questions are answered and we go through two practice rounds that don't affect your earnings, you will engage in the first four periods of the experiment.

Any questions? 


\section{Practice Scripts}

Before the real decision-making begins, we're going to go through two practice rounds the purpose of which is to familiarize you with the way that you enter your choices on your computer screen, the order of choice, and the information you get back after each decision. The earnings shown on your screen for these practice rounds are only illustrative, reflecting decisions I'll be asking you to enter. They have no effect on your real earnings in the experiment. Also, the participants with whom you'll interact in the practice rounds are not the ones in your group for the real decision periods. Please follow our instructions as closely as possible and do not click any buttons until told to.

The first screen you'll see tells you that you and each other person in your group has 100 wealth tokens at the beginning of the experiment. Please click next.

The next screen you'll see in each round tells you the number of wealth tokens and the number of effort tokens with which you begin the round. Please click next.

The next screen is the first in which you have to enter a decision. You should enter the number of effort tokens you want to contribute to collective protection under the heading "Put in Collective Protection."

In this first practice round, please allocate the following number of effort tokens to the group account if the last digit of your seat number is

even and < 6: 1 effort token

odd and < 6: 2 effort tokens

even and $>$ 5: 3 effort tokens

odd and > 5: 4 effort tokens

Notice that in the lower part of the window you can see the number of effort tokens that remain in your account, which automatically updates as you enter your contribution into collective protection. Now click Submit. Note that if all participants haven't yet made their decisions and clicked submit, you'll see a screen saying "Waiting for Others". There is no possibility of seeing what others decide first and then making your own decision.

The next screen shows the total number of effort tokens all group members have contributed to collective protection and the consequent level of collective protection. Click continue.

The next screen you'll see is the decision screen for allocating the remainder of your effort tokens for this period. Notice that the number of effort tokens you have left appears in the top of the window, and this number is updated as you allocate these effort tokens to production, private protection and theft. You have to click on at least some of the boxes below the lines saying "production tokens," "private protection tokens" and "theft tokens", until you finish allocating your effort tokens.

Please use your remaining effort tokens as follows (and do not click submit until we tell you to):

- Assign 3 effort tokens to production and 3 to private protection.

- If you still have any effort tokens left, use them to try stealing from other group members.

- Assign no more than one effort token to stealing from an individual and if you have multiple effort tokens assign them randomly, for instance if you have 2, assign them to any two decision-makers in your group.

Before leaving this screen, please notice the following: (a) you can click on the button labeled "Stats" at the top to learn the number of wealth tokens held by the others in your group; (b) when you enter a number of production tokens, you'll see immediately below that box the number of Wealth tokens you'll produce if you stick with that choice; (c) when you enter a number of private protection tokens, you'll see below that box the total level of security of your wealth token accumulation.

Before clicking on the submit button, please also notice that it is possible to reconsider and to change your allocations at any time until you hit submit. Simply delete any entry you want to change and enter a new value. Also note that you don't need to enter a value into each box. If you enter no value under production tokens, for instance, the computer will understand your production tokens choice to be 0 . The same applies to 
private protection and theft tokens. You can always choose 0 in any case. If the number of effort tokens you use for the round does not sum to 10 in total, you will receive an error message and will have to change entries until all of your effort tokens have been used. If you are ready, click on Submit now.

When everyone has submitted their decisions you'll see a "Round Performance Summary." Please read it and raise your hand if you have any questions about this screen. When you're done, please click on Next.

The next screen gives you information about the wealth token accumulations of each member in your group. Notice that there are two boxes: (1) the upper box shows the accumulations of each group member broken up into gains and losses through production and theft through the period that just ended; (2) the lower box shows the accumulations of each group member broken up into gains and losses through production and theft in the period that just ended. Please click on Next Round.

We'll now run through a second and final practice round. Remember, the practice rounds do not count towards determining your earnings. Again, please follow our instructions for this one last practice round.

Notice that your first screen of the round tells you your updated accumulation of wealth tokens. Note that you begin every round with the same number of effort tokens, 10 . Please click next.

Again, the next screen is for indicating how many effort tokens you want to put in the group account. Notice that you can also click on the Stats button here to view again the accumulations of each group member and the break-down according to production, gains from theft and losses due to theft. If you want the stats to disappear, you can click Hide, otherwise they will go away automatically when you click submit, but you can view them again at the next decision stage.

For this last practice round, please allocate the following number of effort tokens to collective protection if the last digit of your seat number is even and < 6: 4 effort token odd and $<6$ : 3 effort tokens even and > 5: 2 effort tokens odd and > 5: 1 effort tokens

Now click Submit.

At the second allocation screen, please allocate your effort tokens as follows:

- 3 to production,

- 1 to private protection, and

- For your theft choices, please open again the Stats window. In the real experiment, you may want to use the information in that window to help you decide whom you try to steal from. For this practice round, as an illustration, please assign 2 effort tokens to whichever member of your group (excluding yourself) has the smallest accumulation of wealth tokens after Practice 1 (check the stats window). If more than one member is tied for smallest accumulation, choose one randomly to assign your effort tokens to. If you have more effort tokens left, assign 1 token to whichever member of your group has the $2^{\text {nd }}$ smallest accumulation of wealth tokens. If you have more effort tokens left, assign them as you will among the other group members you haven’t tried to steal from yet.

When everyone has submitted their decisions you'll see the Round Performance Summary, as before. When you're ready, please click on Next.

Finally, as before, the next screen gives you information about the wealth token accumulations of each group member broken up into gains and losses through production and theft.

Before we begin the rounds that count toward your real earnings, please note that the time it will take to complete all 24 rounds depends on all of your rates of progress. No individual can move forward until all participants make the corresponding decisions at each stage of the process, which includes, at the end of each period, that you finish viewing your round performance summary and click "next." Please focus on the task and click the appropriate "submit" and "next" buttons as soon as you are ready to do so, so that the process 
can proceed for all in a timely fashion. To help make sure that we finish before we'll remind you to continue if we see that progress stalls. (We can track on our monitor whether actions have been taken but not which actions they were, that information is stored only for later analysis.)

O.k.? Please begin.

\section{E.3 VOTE}

\section{Instructions}

\section{General Information}

This is an experiment aimed at studying decision-making while interacting with other individuals. During the

experiment, you will be earning money in the form of wealth tokens . At the end of the experiment you will be paid in cash in real dollars $(1$ wealth token $=1.4 \mathbb{\Phi})$. The amount you will earn will depend on your and others' decisions. Please read and listen carefully to make sure you understand the decision process. At the end of the instructions you will have a chance to ask questions. The experiment will conclude with a brief questionnaire.

\section{Experiment Structure}

The experiment consists of 24 rounds, organized in 6 sets of 4 rounds. The initial instructions cover the first 4 rounds, which will be followed by further instructions and the remaining 5 sets of 4 rounds. (The first rounds are labeled $1-4$, the remaining ones are labeled $1-20$.) In total, we expect the experiment to last no more than two hours, including the instructions and practice rounds.

\section{Your Group}

At the beginning of the experiment you will be randomly assigned to a group consisting of yourself and four others. Each member of the group will be randomly assigned a subject number (denoted Sub 0 , Sub 1,..., Sub 4) which remains fixed. You will interact exclusively with the people in your group of five throughout the entire experiment. All decisions are made anonymously, so no participant knows the identities of the other decision-makers, nor will you ever be informed who was in your group. Payments are anonymous and will be made in cash at the end of the session.

\section{Communication and questions}

Communication is not allowed at any time during the experiment. If you have any questions, please raise your hand and we will come to assist you. Do not hesitate to call on us.

\section{Other kinds of tokens}

During the experiment, you will have the chance to use two types of tokens. Only wealth tokens will be converted into cash at the end of the experiment. Effort tokens will also play a part, but they only have value insofar as they help you to earn or to conserve wealth tokens.

\section{$\underline{\text { Instructions }}$}

At the beginning of the first round, each member of the group (yourself included) will be endowed with 100 wealth tokens . Each round, each of you will receive 10 effort tokens money value, but they can be used to help you earn or conserve wealth tokens.

In every round, you have to allocate your effort tokens among three alternatives: 
* Produce new wealth tokens 望国.

The table on the right shows the relation between effort tokens (the input) and wealth tokens (the output). For instance, if you allocate 5 effort tokens to production, you produce 55 wealth tokens which are added to your accumulation.

\begin{tabular}{|c|c|}
\hline $\begin{array}{c}\text { \# Effort } \\
\text { Tokens }\end{array}$ & $\begin{array}{c}\text { \# Wealth Tokens } \\
\text { Produced }\end{array}$ \\
\hline 1 & 15 \\
\hline 2 & 28 \\
\hline 3 & 39 \\
\hline 4 & 48 \\
\hline 5 & 55 \\
\hline 6 & 60 \\
\hline 7 & 64 \\
\hline 8 & 67 \\
\hline 9 & 69 \\
\hline 10 & 70 \\
\hline
\end{tabular}

* Steal others' wealth tokens

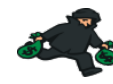
member(s) of the group, such that for every effort token you direct to stealing from, say, member 2, you will have the chance to steal 10 wealth tokens from him/her. The likelihood that your theft attempts succeed depends upon the other member's total degree of security, as described below.

* Protect your own wealth tokens from being stolen

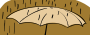
protection, the probability that you will keep your wealth tokens in the event that someone attempts to steal them rises by 10 percentage points. For example, if you put 4 effort tokens into protection, the likelihood that an attempt to steal wealth tokens from you will fail becomes 4 X $10=40 \%$ (in other words, the likelihood that the attempted theft succeeds is only 60\%). The example below illustrates the stealing mechanism as well as the determination of chances.

Example: Member 2 puts 3 effort tokens into protection and member 3 puts 1 effort token into protection. Hence, member 2's degree of protection is 3 X $10=30 \%$, while 3's level of protection is 1 X $10=10 \%$. If you direct 2 effort tokens to an attempt to steal from member 2 and 1 effort token to attempting to steal from member 3, 20 of 2's wealth tokens and/or 10 of 3's wealth tokens may be transferred to you. The likelihood of your theft from 2 succeeding is $100-30=70 \%$, and the likelihood of your theft from 3 succeeding is 100 $-10=90 \%$. The computer will ultimately determine according to the aforementioned probability of $70 \%$ whether 0 or 20 wealth tokens are transferred to you from member 2 (note: there's a $70 \%$ chance of 20 tokens being transferred, a 30\% chance of 0 tokens being transferred, and no chance of an intermediate amount being transferred). Likewise, the computer will independently decide using the probability $90 \%$ whether 0 or 10 wealth tokens are transferred to you from member 3. If a theft is successful, the wealth tokens are deducted from 2's and/or 3's accumulation and are added to yours.

Exception: If the total number of wealth tokens that other members would successfully steal from a particular group member, say member 2, exceeds 2's existing accumulation, then the computer will adjust the size of the transfers, since member 2 cannot end up with a negative number of wealth tokens. For example, suppose members 0, 1, 3 and 4 each direct 3 effort tokens to attempting to steal from Member 2, and that none of the theft attempts is prevented by the action of Member 2's degree of protection, so that a total of 3 X $10 \times 4=$ 120 wealth tokens would be taken from member 2 . And suppose that member 2 has only 100 wealth tokens at this point. Then members $0,1,3$ and 4 would each receive only $100 / 4=25$ rather than 30 wealth tokens. The decision of each to direct 3 effort tokens against member 2 is nevertheless irrevocable; each would have spent 3 effort tokens, though gaining only 25 rather than 30 wealth tokens from it.

At the end of each round, the total number of wealth tokens will be computed according to the following formula:

$$
\begin{aligned}
\text { Wealth tokens }= & \text { Wealth tokens held at the beginning of the round } \\
& + \text { New wealth tokens produced } \\
& + \text { Wealth tokens you stole from other members } \\
& - \text { Wealth tokens other members stole from you }
\end{aligned}
$$


At the end of each round you will learn the statistics of your performance in that round as well as the cumulative statistics through that round. That is, you will find out: (i) the number of wealth tokens produced; (ii) the total number of wealth tokens you sought to steal from others and the number of wealth tokens that you successfully stole; (iii) the number of wealth tokens other group members sought to steal from you and the number of wealth tokens they successfully stole. (Note that the information on (iii) is given as an aggregate; you won't be told which particular group members attempted or succeeded to steal from you.) These amounts will be added/subtracted from the number of wealth tokens that you started the round with, according to the formula described above.

You will also learn about the total accumulation of wealth tokens in the hands of each other group member through that round, and the number of wealth tokens that each group member has thus far obtained by production, the number each has thus far obtained by stealing from others, and the number each has thus far lost by means of theft. This information will be available to you anytime in the following round as you make your allocation decisions.

\section{Payoffs}

Your earnings from this experiment will be the $\$ 5$ that is guaranteed to you simply for participating, plus $1.4 \$$ for every wealth token that you have accumulated by the end of the 24 rounds. Notice that your earnings do not depend on how much you accumulate in comparison to others, only on how much you accumulate.

To make sure that you understand how the different choices operate in the experiment, we'll now provide some examples.

\section{Examples of protection possibilities}

Example 1: Member 1 allocates 5 effort tokens to protection, member 2 allocates 3 effort tokens to protection, and members 3,4 and 5 each use 1 effort token for protection. Their corresponding levels of security are $50 \%, 30 \%, 10 \%, 10 \%$ and $10 \%$, respectively.

Example 2: Group members use various numbers of effort tokens for protection; for example 6 tokens, 4 tokens, 3 tokens, 1 token, and no tokens. They achieve the corresponding levels of security: $60 \%, 40 \%, 30 \%$, $10 \%$ and $0 \%$, respectively.

\section{Examples of the use of effort tokens and payoffs}

In the following examples, we illustrate possible behaviors and the earnings these behaviors would lead to if followed for the entire 24 rounds of the experiment. While the set of decisions to be made will change in some respects after the first 4 rounds, enough remains the same so that calculating payoffs on a 24 round basis is a useful way for you to grasp the earnings consequences of a given scenario.

Example 1: You begin with 100 wealth tokens and each round you use all 10 effort tokens to produce wealth tokens. No group member ever attempts to steal wealth tokens from you. You earn 70 wealth tokens each round, accumulating a total of $100+(70 \times 24)=1780$ wealth tokens. Your earnings in dollars would be $\$ 5+$ $(1.4 \$ \mathrm{X} 1780)=\$ 29.92$

Example 2: You begin with 100 wealth tokens and each round you allocate 2 effort tokens to protection and 8 effort tokens to stealing from others. You can steal up to 80 wealth tokens, and there is an $80 \%(=100-(2 \mathrm{X}$ $10)$ ) chance that any given attempt by others to steal wealth tokens from you will succeed. Your maximum accumulation could be $100+(80 \mathrm{X} 24)=2020$ wealth tokens, but you may earn less than this, possibly much less, if others successfully steal wealth tokens from you and/or if others use effort tokens to provide some security for their accumulations. Using the maximum estimate of 2020 wealth tokens, your accumulated earnings in dollars would be $\$ 5+(1.4 \$$ X 2020 $)=\$ 33.28$

Example 3: You begin with 100 wealth tokens and each round you and others in your group use four effort tokens for production, two effort tokens for protection, and four effort tokens for stealing, assigning one token to stealing from each other group member. You produce 48 wealth tokens, and your protection level each period is $20 \%$. The other members of your group each attempt to steal 10 wealth tokens from you and 
succeed in $80 \%$ of attempts, hence reducing your wealth token accumulation by 4 X $10 \times 0.8=32$ wealth tokens per period, on average. Your four attempts to steal 10 wealth tokens from other members succeed on $80 \%$ of attempts, thus adding 4 X 10 X $0.8=32$ wealth tokens to your accumulation per period, on average. Your wealth token accumulation thus rises by an average total of 48 per period, earning you a total of $100+$ $(48$ X 24) $=1252$ wealth tokens, for earnings of $\$ 5+(1.4 \pitchfork \times 1252)=\$ 22.53$

Example 4: You begin with 100 wealth tokens and each round you put 3 effort tokens into protection and assign the remaining 7 effort tokens to production. Suppose other members also put 3 effort tokens into protection each period. The likelihood that a theft attempt will succeed is $100-(10 \mathrm{X} \mathrm{3})=70 \%$. Your 7 effort tokens produce 64 wealth tokens for you each round. You can accumulate up to $100+(64 \mathrm{X} 24)=$ 1636 wealth tokens, but you may earn less if others steal tokens from you. Using the maximum estimate of 1636 wealth tokens, your total earnings would be $\$ 5+(1.4 \$ \mathrm{X} 1636)=\$ 27.90$

Note that the behavior does not change across rounds in these examples, but this is just for the sake of making these illustrations easy to understand. In fact, your strategy can change over time. As can be seen, there are an almost infinite number of possible outcomes, depending on your decisions and the decisions of others in your group.

After questions are answered and we go through two practice rounds that don't affect your earnings, you will engage in the first four periods of the experiment.

Any questions?

\section{Instructions for the remaining 20 rounds}

The following are the additional instructions that you will need for the remaining 20 rounds of the experiment. You will continue to interact with the same group of participants that you interacted with during the first 4 rounds. As before, you will not be identified to one another other than by the subject number, either during or after the experiment, and there must be no communication.

During the remaining rounds, you continue to receive 10 effort tokens round, which you can use to produce

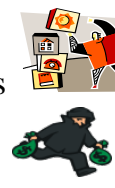
at the beginning of each wic

protect if your wealth tokens from being stolen by others. The computer has recorded your wealth token accumulation so far and will count it towards your final earnings. However, each of you will begin the remaining rounds with a fresh allotment of 100 wealth tokens and you will be shown your earnings in the remainder of the experiment accumulating from this new starting point.

In addition to the three uses of effort tokens that are already familiar to you, there is now an additional way in

which effort tokens can be used, called collective protection the private protection activity that has been available until now in three ways. First, an effort token allocated to collective protection increases the security of the wealth accumulations of all members of the group, not only that of the person who allocated it. Second, an effort token allocated to collective protection reduces the probability of a successful theft by $6 \%$, not the $10 \%$ associated with private protection tokens (but note that this $6 \%$ affects all five group members whereas the $10 \%$ impact of a token allocated to private protection affects only one group member-you). Third, allocation of tokens to collective protection takes place in a separate, initial stage of the round, and the total level of collective protection is known to all group members when they make their allocation decisions regarding the remaining three activities (production, stealing, and private protection), whereas the level of an individual's private protection is not known to others when they make those decisions.

A further detail about collective protection is that there is a maximum achievable level of collective protection that is reached if group members put a total of 12 or more tokens into this activity. That is, $72 \%(6 \% \mathrm{X} 12)$ is 
the largest amount by which the probability of successful theft can be reduced by collective protection. If group members allocate 13 or more effort tokens to collective protection, the protection level remains at $72 \%$ (an attempt at theft succeeds with $28 \%$ probability). However, allocations to private protection add to the total protection level of an individual. For example, suppose that 7 tokens are allocated to collective protection, giving a protection level of $6 \% \times 7=42 \%$. If you then allocate 4 tokens to private protection, your own protection level is $42 \%+(10 \% \mathrm{X} 4)=82 \%$. Of course, your level of protection from theft cannot exceed $100 \%$, so at some point additional tokens allocated to private protection have no effect. For example, if the collective protection level is $72 \%$ and you allocate 4 tokens to private protection, the third of your 4 tokens brings your protection level to $100 \%$ and the fourth produces no further change.

Although allocations to collective protection always take place in a distinct first stage of each round, there are two different ways in which the allocation decisions can be made. At the beginning of each set of 4 rounds, your group decides by majority vote which of these two schemes will be used in those rounds.

$>$ Scheme 1 (Decide Individually): at the start of every round, each group member decides independently how many of her/his 10 effort tokens to contribute to collective protection.

$>$ Scheme 2 (Decide by Vote): at the start of every round, each group member votes for a number of effort tokens s/he would like all five group members to be required to put into collective protection. The choices of the five of you will be ordered from lowest to highest, and the amount that lies in the middle will be selected. That amount will then be deducted automatically from the ten effort tokens with which each member begins the round.

Once the choice between Schemes 1 and 2 has been made by majority vote in your group, it will be in force for the next four periods of the experiment, after which your group will vote again on the scheme that will be used to define the individual contributions to collective protection for the subsequent four rounds.

Whereas votes on schemes take place before each set of four rounds, each round itself consists of two stages. In stage 1 , each group member either makes her/his contribution to collective protection (if Scheme 1 is in place), or votes for a contribution amount and has the amount decided on deducted automatically (if Scheme 2 is in place). In stage 2, each group member has to allocate her/his remaining effort tokens among the three remaining alternatives of private protection, production and theft. The impact of tokens allocated to each of those three activities remains exactly as in the first four rounds.

To make sure that you understand how collective and private protection work in the experiment, we'll now provide some examples beginning with Scheme 1 (Decide Individually).

\section{Examples with individual choice of collective protection (Scheme 1)}

Example 1. Three members each contribute two effort tokens and two members each contribute three effort tokens to collective protection, for a total of 12 , giving a protection level of $72 \%$ to everyone. Nothing is spent on private protection, so every member equally enjoys a $72 \%$ level of-protection.

Example 2. No member contributes any effort tokens to collective protection. Each member uses three effort tokens for private protection. They each achieve a security level of $30 \%$.

Example 3: Two members each contribute two effort tokens to collective protection, while the other members each contribute three, one, and zero effort tokens, respectively. In total, 8 effort tokens are contributed to collective protection, which provides a security level of $48 \%$ to everyone. Members individually use various numbers of effort tokens for private protection; for example 6 tokens, 4 tokens, 3 tokens, 1 token, and no tokens. They achieve the corresponding levels of security: $100 \%, 88 \%, 78 \%, 58 \%$ and $48 \%$, respectively.

\section{Examples with voted choice of collective protection (Scheme 2)}

Example 1: Subject 0 votes to require that 4 effort tokens be contributed to collective protection; subject 1 votes for 2; subject 2 for 3 ; subject 3 for 0 and subject 4 for 1 . From lowest to highest, we arrange the amounts for which subjects voted as: $0,1,2,3,4$. The amount that lies in the middle is 2 . Therefore, every group member will have 2 effort tokens deducted from her/his endowment of 10 effort tokens and assigned to collective protection. The level of collective protection from the $2 \mathrm{X} 5=10$ tokens is calculated as before, i.e., $10 \times 6 \%=60 \%$. Nothing is spent on private protection, so every member equally enjoys a $60 \%$ level of protection. 
Example 2: Subject 0 votes for requiring 3 effort tokens to be contributed to collective protection; subject 1 votes for 1 ; subject 2 for 0 ; subject 3 for 1 and subject 4 for 2 . From lowest to highest, we arrange the proposals as follows: $0,1,1,2,3$. Although there are two votes for 1 , one of these counts as the middle proposal. Therefore, every group member is obligated to contribute 1 effort token to collective protection, so there is an automatic deduction of 1 effort token from each individual's endowment of 10 effort tokens. The 5 tokens put into collective protection yield a collective protection level of $5 \mathrm{X} 6 \%=30 \%$. Members individually use various amounts of effort tokens for private protection; for example 6 tokens, 4 tokens, 3 tokens, 1 token, and no tokens. They achieve the corresponding levels of security: $90 \%, 70 \%, 60 \%, 40 \%$ and $30 \%$, respectively.

Other examples on the determination of contributions to collective protection under Scheme 2:

Votes are for 0, 0, 0, 2, 3 Decision: everyone contributes 0

Votes are for $0,1,2,3,3$ Decision: everyone contributes 2

Votes are for $0,1,3,4,5$ Decision: everyone contributes 3

Votes are for $0,3,4,4,7$ Decision: everyone contributes 4

Examples illustrating how the full set of decisions can lead to different overall earnings in the experiment were given in the previous instructions. Are there any questions before we begin the practice rounds?

\section{Practice Scripts}

\section{Practice for first 4 rounds}

Before the first real set of 4 rounds begins, we're going to go through two practice rounds the purpose of which is to familiarize you with the way that you enter your choices on your computer screen, the order of choice, and the information you get back after each decision. The earnings shown on your screen for these practice rounds are only illustrative, reflecting decisions I'll be asking you to enter. They have no effect on your real earnings in the experiment. Also, the participants with whom you'll interact in the practice rounds are not the ones in your group for the real decision periods. Please follow our instructions as closely as possible and do not click any buttons until told to.

The first screen you'll see tells you that you and each other person in your group has 100 wealth tokens at the beginning of the experiment. Please click next.

The next screen you'll see in each round tells you the number of wealth tokens and the number of effort tokens with which you begin the round. Please click next.

The next screen is where you have to enter your allocation choices to production, protection and theft. You have to click on at least some of the boxes below the lines saying "production tokens," "protection tokens" and "theft tokens", until you finish allocating all your effort tokens.

Please use your effort tokens as follows (and do not click submit until we tell you to):

- Assign 5 effort tokens to the production of new wealth tokens and 3 to the protection of your existing wealth tokens.

- $\quad$ Randomly assign your remaining 2 effort tokens to stealing from other members of your group.

Before leaving this screen, please notice the following: (a) you can click on the button labeled "Stats" at the top to learn the number of wealth tokens held by the others in your group; (b) when you enter a number of production tokens, you'll see immediately below that box the number of Wealth tokens you'll produce if you stick with that choice; (c) when you enter a number of protection tokens, you'll see below that box the total level of security of your wealth token accumulation.

Before clicking on the submit button, please also notice that it is possible to reconsider and to change your allocations at any time until you hit submit. Simply delete any entry you want to change and enter a new value. Also note that you don't need to enter a value into each box. If you enter no value under production 
tokens, for instance, the computer will understand your production tokens choice to be 0 . The same applies to protection and theft tokens. You can always choose 0 in any case. If the number of effort tokens you use for the round does not sum to 10 in total, you will receive an error message and will have to change entries until all of your effort tokens have been used. If you are ready, click on Submit now.

Note that if all participants haven't yet made their decisions and clicked submit, you'll see a screen saying "Waiting for Others". There is no possibility of seeing what others decide first and then making your own decision.

When everyone has submitted their decisions you'll see a "Round Performance Summary." Please read it and raise your hand if you have any questions about this screen. When you're done, please click on Next.

The next screen gives you information about the wealth token accumulations of each member in your group. Notice that there are two boxes: (1) the upper box shows the accumulations of each group member broken up into gains and losses through production and theft through the period that just ended; (2) the lower box shows the accumulations of each group member broken up into gains and losses through production and theft in the period that just ended. Please click on Next Round.

We'll now run through a second practice round, which will be the last before the first real rounds begin. Remember, the practice rounds do not count towards determining your earnings. Again, please follow our instructions for this second practice round.

Notice that your first screen of the round tells you your updated accumulation of wealth tokens. Note that you begin every round with the same number of effort tokens, 10 . Please click next.

Again, the next screen is for indicating your allocation choices to production, protection and theft.

Notice that you can also click on the Stats button here to view again the accumulations of each group member and the break-down according to production, gains from theft and losses due to theft. If you want the stats to disappear, you can click Hide, otherwise they will go away automatically when you click submit, but you can view them again at the next decision stage.

At the second allocation screen, please allocate your effort tokens as follows:

- 6 to production,

- 1 to protection, and

- For your theft choices, please open again the Stats window. In the real experiment, you may want to use the information in that window to help you decide whom you try to steal from. For this practice round, as an illustration, please assign 2 effort tokens to whichever member of your group (excluding yourself) has the smallest accumulation of wealth tokens after Practice 1 (check the stats window). If more than one member is tied for smallest accumulation, choose one randomly to assign your effort tokens to. Finally, assign 1 effort token to whichever member of your group has the $2^{\text {nd }}$ smallest accumulation of wealth tokens.

When everyone has submitted their decisions you'll see the Round Performance Summary, as before. When you're ready, please click on Next.

Finally, as before, the next screen gives you information about the wealth token accumulations of each group member broken up into gains and losses through production and theft.

Before we begin the rounds that count toward your real earnings, please note that the time it will take to complete all 24 rounds depends on all of your rates of progress. No individual can move forward until all participants make the corresponding decisions at each stage of the process, which includes, at the end of each period, that you finish viewing your round performance summary and click "next." Please focus on the task and click the appropriate "submit" and "next" buttons as soon as you are ready to do so, so that the process can proceed for all in a timely fashion. To help make sure that we finish before _ _ _, we'll remind you to continue if we see that progress stalls. (We can track on our monitor whether actions have been taken but not which actions they were, that information is stored only for later analysis.) 
O.k.? Please begin.

\section{Practice Rounds for remaining 20 rounds}

\section{(Practice under independent contribution)}

Before proceeding with the remaining 20 rounds, we're going to go through two practice rounds the purpose of which is to familiarize you with the procedure for voting on which of the two schemes for determining the level of collective protection will be used by your group, as well as to familiarize you with the collective protection technology itself. As before, the earnings shown on your screen for these practice rounds are only illustrative and have no effect on your real earnings in the experiment. Please follow our instructions as closely as possible and do not click any buttons until told to.

The first screen you'll see tells you that you and each other person in your group has 100 wealth tokens at the beginning of the remaining rounds. Please click next.

The next screen you'll see asks you to indicate which of the two schemes under which the level of collective protection can be determined you prefer. For this practice round, please all vote for "Decide individually", whereby each group member decides independently how many effort tokens to contribute to collective protection. Click next.

The next screen shows the result of the vote. Since everyone in the group voted for determining contributions into collective protection independently, this is in fact the scheme that will be used for this practice round.

The next screen you'll see in each round tells you the number of wealth tokens and the number of effort tokens with which you begin the round. Please click next.

The next screen is for indicating how many effort tokens you want to contribute to collective protection. Please allocate the following number of effort tokens to the group account

if the last digit of your seat number is

even and <6: 1 effort token

odd and $<6$ : 2 effort tokens

even and > 5: 3 effort tokens

odd and > 5: 4 effort tokens

Notice that in the lower part of the window you can see the number of effort tokens that remain in your account, which automatically updates as you enter your contribution into collective protection. Click submit.

The next screen shows the total number of effort tokens all group members have contributed to collective protection and the consequent level of collective protection. Click continue.

The next screen you'll see is the decision screen for allocating the remainder of your effort tokens for this period. Notice that the number of effort tokens you have left appears in the top of the window, and this number is updated as you allocate these effort tokens to production, private protection and theft. You have to click on at least some of the boxes below the lines saying "production tokens," "private protection tokens" and "theft tokens", until you finish allocating your effort tokens.

For purposes of this practice round, please use your remaining effort tokens as follows (and do not click submit until we tell you to):

- Assign 3 effort tokens to production and 3 to private protection.

- If you still have any effort tokens left, use them to try stealing from other group members, distributing them randomly among the other group members.

Before leaving this screen, please notice that when you enter a number of private protection tokens, you'll see below that box the total (i.e., collective protection + private protection) level of security of your Wealth token accumulation. Click on Submit now. 
As before, the next two screens provide the "Round Performance" summary and the information about the wealth token accumulations of each member in your group. Please click on Next and Next Round, accordingly.

\section{(Practice under voting scheme)}

We'll now have a practice round using the scheme in which the contributions to collective protection are determined by vote.

There is again a first screen telling you that you have an endowment of 100 wealth tokens. This screen will in fact only appear at the beginning of the first of the remaining rounds..

The next screen is again the one in which you vote for one or the other of the two schemes for determining contributions to collective protection. (Recall that you will actually vote on the scheme only at the beginning of each set of four rounds, not in every round. The remaining 20 rounds are renumbered beginning from 1 , so the votes are before round 1 , round 5 , round 9 , round 13 , and round 17 . Here you're voting on the scheme during consecutive rounds in order to get you familiar with both schemes.) Please all vote for "Decide by vote (middle preference binding)" whereby each group member votes for a number of effort tokens he or she would like all five group members to be required to put into collective protection, and the amount that lies in the middle will be selected. Click next.

The next screen shows the result of the vote. Since everyone in the group voted for determining contributions into collective protection by majority vote, this is in fact the scheme that will be used for this practice round.

The next screen you'll see tells you the number of wealth tokens and the number of effort tokens with which you begin the round. Please click next.

In the next screen, you'll put a number into the box under the heading "Enter the number of tokens you wish to have all group members including yourself put into Collective Protection.” Please vote for having the following number of effort tokens put into collective protection:

if the last digit of your seat number is

even and < 6: 4 effort tokens

odd and < 6: 3 effort tokens

even and > 5: 2 effort tokens

odd and > 5: 1 effort token

When everyone has cast their vote, you'll see what the group selected as the number of effort tokens that will be contributed by each group member in the round and the consequent level of collective protection. You will also see the number of effort tokens that remain in your account. Notice that the amount that the group decided on (i.e., the middle number among those selected by the five group members) is automatically deducted from your endowment of 10 effort tokens. Click next.

At the second allocation screen, please enter the following decisions (and do not click submit until we tell you to):

- First, assign 3 effort tokens to production and 1 to private protection.

- Then, allocate the remainder of your effort tokens to theft, assigning them randomly among the other members of your group.

You may now submit the allocation. The next two screens show your performance summary and the accumulation of wealth tokens by each group member. Click Next as you finish looking at this information. This ends our two practice rounds.

Any questions? Please begin. 